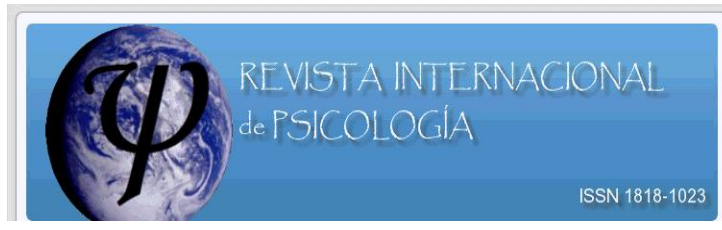

\title{
Funcionamiento Familiar en Amas de Casa Mexicanas cuando la Pareja Emigra
}

\section{Family Functioning in Mexican Housewives when Couples Emigrate}

\author{
Erika Robles Estrada
}

Hans Oudhof van Barneveld

Aída Mercado Maya

\section{Nota sobre los Autores}

Erika Robles Estrada, Hans Oudhof van Barneveld, Aída Mercado Maya. Todos los autores de la Facultad de Ciencias de la Conducta, Universidad Autónoma del Estado de México. Dirección postal: Filiberto Gómez s/n Barrio de Tlacopa, Col. Guadalupe, C.P. 50010, Toluca, México. Correo electrónico: erikarobles@yahoo.com. Teléfono (722) 2720076.

Remita cualquier duda sobre este artículo al siguiente domicilio: Facultad de Ciencias de la Conducta, Universidad Autónoma del Estado de México. Dirección postal: Filiberto Gómez s/n Barrio de Tlacopa, Col. Guadalupe, C.P. 50010, Toluca, México. Correo electrónico: erikarobles@yahoo.com 


\section{Resumen}

Entre otros países, México ha sido a través de la historia uno de los principales países con la mayor tasa de emigrantes económicos hacia Estados Unidos de América. En la década de los setenta había 879 mil personas (Zúñiga, 2004; INEGI, 2015). Sin embargo, en 2003 la cifra se elevó hasta 26.7 millones contabilizando también a sus descendientes (Zúñiga, 2004; INEGI, 2015). Tradicionalmente, es el padre de familia quien emigra dejando a la familia en su país natal. Por tanto, es preciso cuestionarse lo siguiente: ¿Cómo perciben las amas de casa el funcionamiento familiar cuando la pareja emigra a Estados Unidos de América? En este estudio, el funcionamiento familiar se conceptualizó en términos de resolución de problemas, comunicación, roles, involucramiento afectivo, respuestas afectivas y control de conducta. Seleccionamos la aproximación del enfoque sistémico para abordar el concepto de funcionamiento familiar. Este es un estudio cualitativo con diseño fenomenológico psicológico del funcionamiento familiar. La muestra consistió en 10 mujeres del municipio de Tonatico, Estado de México, cuyas parejas eran migrantes económicos en EE. UU. Usamos el grupo focal y la narrativa como técnicas cualitativas para recolectar los datos. Descubrimos 14 temas del funcionamiento familiar. De estos temas, 8 estaban relacionados con aspectos instrumentales y 6 con aspectos afectivos. Con la partida de la pareja, las participantes percibieron el funcionamiento familiar como un proceso de ajuste continuo, con implicaciones afectivas e instrumentales. Concluimos que en el contexto mexicano, la migración del padre de familia impacta severamente en el funcionamiento de la familia.

Palabras clave: funcionamiento familiar, migración, amas de casa. 


\section{Abstract}

Mexico, among other countries, has had throughout history the highest rate of economic migrants towards the United States of America. In the 1970s, there were 879 thousand economic migrants (Zuñiga, 2004; INEGI, 2015). Nonetheless, in 2003 the number increased to 26.7 million including their descendants (Zuñiga, 2004; INEGI, 2015). Traditionally, the family man is the one who emigrates leaving his family in the home country. Therefore, how do housewives perceive family functioning when their partners have emigrated to the United States? In this study, family functioning was conceptualized in terms of the following: problem solving, communication, roles, affective involvement, affective responses and behavioral control. We chose the systemic theory approach to address the family functioning concept. This is qualitative, psychological phenomenological study of family functioning. We sampled 10 women from Tonatico, State of Mexico, whose partners were economic migrants in the US. As qualitative techniques, we used focus group and narrative inquiry. We found 14 family functioning themes. Out of these themes, 8 were associated with instrumental aspects and 6 with affective ones. Based on the partner's departure, participants perceived family functioning as a continuous adjustment process, with affective and instrumental implications. We concluded that, in the Mexican context, the family man's emigration has a severe impact on family functioning.

Keywords: family functioning, migration, housewives. 


\section{Introducción}

Al remitirnos a los antecedentes de los estudios sobre familia, es posible observar que los primeros se centraron es aspectos cuantificables, como su estructura, vivienda y número de habitantes. Desde la perspectiva de Membrillo, Fernández, Quiroz y Rodríguez (2008), esto corresponde a un contexto positivista, dejando fuera a otros enfoques teóricos que han sido la base para estudiar a la familia desde otras miradas, como en sus relaciones, el conflicto, la crianza, su dinámica y funcionamiento, entre otras.

No obstante, hay temáticas que desde la perspectiva psicológica que es preciso continuar estudiando, una de ellas es el caso de la migración parental y sus repercusiones en la vida familiar. En este sentido, Sandoval, Román y Salas (2013) y Martín (2007) señalan que es contradictorio que siendo México un país en el cual la migración es arraigada, ni hogar, ni familia hayan sido considerados como tema central en los estudios.

El fenómeno de la migración es tan viejo como la humanidad misma y tiene diversas causales asociadas a problemáticas económicas, de seguridad, ambientales, culturales, políticas o personales (Andrade, Alvis, Jiménez, Redondo \& Rodríguez, 2016), en las cuales se ve inmerso el sistema familiar. Tomó fuerza a mediados del siglo XIX, en la que surgió y se fortaleció la sociedad industrial, caracterizada por la modernización, mayores ofertas laborales e incremento económico (Elizaga \& Macisco, 1972).

El Instituto Nacional de Estadística y Geografía (INEGI, 2010), señala que la migración cuando las personas se mudan de su lugar de residencia de manera temporal o definitiva con la intención de mejorar su situación en algún ámbito de su vida; puede presentarse a nivel municipal, estatal o internacional.

La migración internacional es más compleja de lo que parece en la vida de la familia, pues cuando el padre parte, tiene que reestructurarse de manera interna y adaptarse 

impacta en la familia de diversas formas.

El principal destino de los mexicanos es EE. UU. debido a su colindancia. Desde 1970 la migración aumentó considerablemente con 879 mil personas; para el 2003 el número fue de 9.9 millones y considerando a sus descendientes, se elevó de 5.4 millones a 26.7 en el mismo periodo; estas cifras colocaron a México como el país con mayor número de migrantes (Zúñiga, 2004). Para Durand (2000), este es un “(...) fenómeno social particular y diferente” (p. 19) de otros movimientos migratorios que se explica a partir de tres elementos; la historicidad que es alusiva a la antigüedad con la que se ha presentado (más de 100 años); la vecindad al compartir la frontera norte, aunque caracterizada por una relación conflictiva debido a las diferencias culturales entre países; y la masividad por posicionarse como “(...) el fenómeno migratorio contemporáneo más grande del mundo" (p. 29) en el cual la colectividad mexicana se ha posicionado como una minoría que ocupa el segundo lugar en Estados Unidos.

Aunado a esto, otro factor que contribuyó a aumentar los índices de migración fue el Tratado de Libre Comercio de América del Norte (García, Lozano, Luis \& Zavala, 2011), aunque pudiera pensarse que el crecimiento de la economía en México la detendría, se continuó percibiendo a EE. UU. como un país de mejores oportunidades.

Por otro lado, también podemos pensar que las actuales políticas migratorias implementadas en el país vecino y las condiciones de peligro a las que se exponen los que desean cruzar, se obstaculiza y/o aminora el tránsito, pero lo real es que la cifra es aún alta, según lo reporta el INEGI (2015) al indicar que del total de personas que salieron del país, el 86.3\% se marchó a Estados Unidos. Incluso, Martínez (2017) señala que se presentó la mayor 
Ante este panorama, planteamos la pregunta de investigación: ¿Cómo perciben las amas de casa el funcionamiento familiar cuando la pareja emigra a Estados Unidos de América? El funcionamiento familiar hace alusión a la resolución de problemas, la comunicación, los roles, el involucramiento afectivo, respuestas afectivas y el control de conducta. Estas categorías se enmarcan en el enfoque sistémico, el cual argumenta que los miembros entre sí son interdependientes. De tal manera que con la partida del padre se pretende identificar cómo funciona la familia. A su vez, este enfoque los estudiamos con base en el paradigma de la psicología fenomenológica.

\section{Revisión de la Literatura}

\section{México y la Migración a Estados Unidos de América}

Entre las causales principales de la migración internacional, el INEGI (2015) marca la búsqueda de oportunidades laborales $(67.8 \%)$, reencontrarse con la familia $(14.4 \%)$, cursar estudios (12.4\%), regularizar su situación migratoria $(0.8 \%)$ e inseguridad pública y violencia $(1.0 \%)$.

Se presenta con mayor frecuencia en zonas rurales de México, caracterizadas porque los habitantes tienen menor acceso a los diversos servicios; como de salud y educativos, a servicios básicos de vivienda (luz, agua potable, drenaje, alumbrado público), incluso el tener una alimentación de calidad no es tarea fácil, motivos por lo que es común que el padre o quien tenga el papel de jefe de familia migre como un último recurso para mejorar sus condiciones de vida. Al respecto, Agustín (2004) señala que para muchos seres humanos, su lugar nativo es un lugar poco amigable para desarrollarse de manera integral, por lo que 


\section{Tonatico, Estado de México: Municipio con Tradición Cultural Migratoria}

Los Estados de la República Mexicana que muestran mayor migración internacional de acuerdo Censo de Población y Vivienda del INEGI en el 2010, son Guanajuato $(116,235)$, Michoacán (83,642), Jalisco (79,001), Estado de México (67,595), Puebla $(66,773)$ y Veracruz $(59,772)$.

Como podemos observar, la migración en el Estado de México es frecuente en el sur de la entidad, específicamente en el Municipio de Tonatico, con giro agricultor y catalogado como "pueblo con encanto" por su giro turístico. Sandoval y Guerra (2010), lo consideran con gran tradición cultural migratoria a la Unión Americana desde las primeras décadas del siglo XXI, por lo que realizan una profunda investigación en materia de migración internacional, motivo por el cual retomamos algunas ideas referidas en su obra a manera de contextualizar:

- Celebran "El día del migrante ausente" que inicia siempre en la segunda semana de enero, concluyendo la primera de febrero.

- La migración socialmente es una costumbre.

- Tradición, redes sociales y familiares se involucran en la partida, hay un circuito migratorio social que induce a muchos niños centrar sus expectativas partir al otro lado.

- Las ciudades en las que se establecen son Waukegan, Milwaukee, Chicago y California. Los empleos que realizan son de agricultura y de servicios (limpieza, restaurantes, hoteles, artesanías y un poco en el pequeño comercio). 
- Envían remesas económicas, cooperan para las fiestas del pueblo fuegos

pirotécnicos y emprenden negocios (misceláneas, cibercafés y posadas familiares).

- Existen un intercambio cultural entre Estados Unidos y Tonatico, es decir, las que llegan del país de residencia (celebraciones tradicionales) y las que se llevan de su lugar natal (fiestas patronales).

- La llegada al pueblo la programan en función de las fiestas religiosas: del municipio la virgen de la Candelaria, la Semana Santa, la virgen de Guadalupe y el día de muertos.

- Lo migrantes y familiares hacen uso de las tecnologías de la información y comunicación.

\section{La Migración Paterna como un Proceso de Ajuste}

La migración internacional conlleva múltiples efectos, Casasa (2008) señala que, a nivel social, impacta en aspectos como de la vida individual y colectiva, económica, demográfica, política, psicológica y cívica. En lo cultural, tiene que ver con las añoranzas de los usos y costumbres del lugar natal, la tendencia a idealizar la casa (hogar) y el extrañamiento en el cual se recuerdan imágenes de la familia unida, utensilios domésticos, rituales, canciones y comidas (Agustín, 2004). Tiene efectos mayores que la muerte de un ser querido porque se pierden: parientes y amigos, a veces la lengua natal y costumbres; asimismo, existen la fantasía de que se regresa o hay reuniones futuras; algunos elementos compensatorios son la esperanza de mejorar económicamente, oportunidades educacionales, políticas y/o sociales (Falicov, 2001). El dejar a la familia es sin duda, uno de los efectos que implica quebrantos familiares, afectivos, y materiales.

Si bien, son evidentes los efectos sociales y culturales que conlleva la migración, nuestro interés es la familia como sistema, su subjetividad respecto a la ausencia del padre 

familia?

Cuando el padre migra, el primer cambio ocurre es en la estructura familiar (Caballero, Leyva-Flores, Ochoa Martín, Zarco \& Guerrero, 2008), para Becerra (2014) al no mantenerse juntas las figuras parentales, la monoparentalidad se hace presente. AlcaldeCampos y Pávez (2013) señalan el aumento de estas formas familiares prevalentes en los países latinoamericanos, ya que este fenómeno se ha producido con mayor intensidad que en otros países del mundo. Por su parte Ariza y D’Aubeterre la llaman conyugalidad a distancia, la cual implica (apoyándose en las telecomunicaciones) continuas negociaciones entre los cónyuges respecto a los procesos de producción y reproducción que involucran el hogar, la fidelidad femenina es obligatoria, así como el cuidado de los hijos y pertenencias del marido (citados en García et al., 2011).

Aún no hay un hay idea clara y generalizable de cómo conceptualizar a las familias en esta condición, lo que es claro es que rompe con las concepciones tradicionales, para Martín (2007), va más allá del parentesco, consanguinidad, tiempo y geografía. Esta noción, nos lleva a pensar en otras concepciones de familia, como la propuesta por Palacios y Rodrigo (2014), en la que se privilegia el tener un proyecto de vida, pertenecer, compromiso entre cada uno de los miembros y relaciones con intimidad, reciprocidad y dependencia.

Esta idea es acorde porque involucra aspectos afectivos sostenibles en la distancia y en el tiempo, asimismo, involucra enfrentar la vida cotidiana, resolver problemas, cumplir con un rol dentro y fuera del hogar y relacionarse con otras personas.

Es preciso señalar que la migración afecta de manera drástica a los integrantes de la de la familia. López (2007) en su análisis sobre migración, mujeres y salud emocional, puntualiza que con la migración del jefe de familia, son las mujeres y los niños quienes se 
ven afectados en su equilibrio psicológico y emocional. Asimismo, señala que son ellas quienes asumen en general las responsabilidades, como la administración de las remesas, el cuidado de los hijos, de la parcela, de los animales, e incluso hacer frente al acoso de los hombres; concluye diciendo que todo esto, son generadores de estrés, ansiedad y problemas físico-emocionales.

Al respecto, Intervida (2004) señala que al involucrar mayoritariamente la migración a la población masculina da lugar a cambios en el reparto tradicional de actividades familiares, las esposas tienen una carga laboral mayor para sacar adelante sus familias; de ahí que busquen apoyo en otras personas. El apoyo social puede implicar "la adición de otros familiares, amigos, compañeros de escuela y/o trabajo y miembros de la comunidad donde se desarrolla el individuo" (García, et al., 2011, p. 267).

Algunos cambios que viven las esposas de los migrantes, se muestran en el estudio de Caballero et al. (2008) en el cual se indagó entre otros aspectos, la composición familiar con mujeres de una comunidad urbana y otra rural del centro de la República Mexicana cuyo compañero había migrado a Estados Unidos; sus hallazgos revelaron que aquellas que tenían hijos pequeños, fueron a vivir con la familia de origen o política por decisión del compañero, con el objetivo de que estuvieran acompañados y protegidos, implicando así mayor control. También encontraron que para que la pareja se mantuviera, era fundamental la comunicación (llamadas telefónicas, cartas y fotografías), así como el envío de dinero con regularidad. En esta investigación las búsquedas de redes de apoyo son fundamentales, pues ayudan a enfrentar problemáticas cotidianas, son fuente de afecto y compañía y apoyan en el cuidado de los hijos.

Hallazgos similares mostraron Del Ángel y Rebolledo (2009) en 38 grupos familiares con ausencia del proveedor económico de cuatro localidades de Veracruz Central, México, 
en donde el $71 \%$ de los casos, envían remesas a un grupo familiar extenso en el cual su familia conyugal se encuentra inserto y bajo el cuidado de los varones (padre y hermanos), lo cual provocó que la esposa perdiera independencia sometiéndose a su autoridad.

En ambos estudios se observa el papel relevante que juega la familia de origen y política con las familias de los migrantes como cuidadores principales, no obstante, la presencia del jefe de familia en el hogar es de vital importancia, pues como señala Palacios, Hidalgo y Moreno (2014), son los que ordenan el contexto familiar y configuran la vida cotidiana mediante la relación con su esposa e hijos. Es decir, el padre es figura clave en el funcionamiento familiar, coadyuva junto con la madre a proporcionar seguridad y estabilidad a los hijos.

Esto empata con el enfoque sistémico, en el que la familia es considerada un sistema que se organizan en subsistemas (padres, hijos, hermanos) y se relacionan con su entorno, de ahí que su poder condicionante no se determine por los lazos consanguíneos, sino por su tipo de funcionamiento, los vínculos afectivos, las interacciones, la comunicación, los roles y tareas para satisfacer las necesidades de sus integrantes (Zanatta, 2013).

Ante el panorama complejo de la migración del padre, en esta investigación planteamos como objetivo analizar la percepción de madres de familia sobre el funcionamiento familiar cuando el jefe de familia migra a EE. UU.

\section{Funcionamiento Familiar}

Una familia que se ha habituado a cierto número de integrantes ha establecido su propio funcionamiento familiar, pero al salir uno de ellos del sistema, tiene que reestructurarse, situación que se presenta cuando el padre migra. La entrada o salida de un miembro genera cambios en el interior como los roles, la interrelación y la comunicación; y 
(Martín, 2007).

De tal manera que, en esta investigación utilizamos el modelo de funcionamiento familiar del Modelo McMaster, el cual se basa en el enfoque sistémico y cuya solidez radica en que es resultado del trabajo continuo durante 30 años en el área clínica, la investigación y docencia con familias (Palomar, 1998).

La evidencia empírica es abundante, en EE. UU. Epstein en conjunto con sus colaboradores han trabajado continuamente este modelo (Epstein, Bishop \& Levin, 1978; Epstein, Baldwin \& Bishop, 1983). En México, una pionera es Atri y Zetune (2006), quien conceptualiza el funcionamiento familiar como la forma en que la familia se desarrolla y funciona como sistema y determina con ello la salud emocional de sus miembros como individuos. Asimismo, Atri y Zetune (2006), creó el Cuestionario de evaluación del funcionamiento familiar, el cual se utilizó en investigaciones subsecuentes (González \& González, 2008; González, Zanatta \& Sánchez, 2011; Guadarrama, Márquez, Veytia, \& León, 2011; Plascencia, Eguiluz \& Osorio, 2016). Cabe señalar que el aporte central de Atri y Zetune (2006) es la puntualización de las dimensiones del modelo, mismas que en esta investigación retomamos como categorías y son descritas a continuación:

a. Resolución de problemas: Es la habilidad de la familia para la resolución de sus problemas, es un factor de protección del funcionamiento familiar; se divide en problemas instrumentales (referentes a la subsistencia en la vida diaria) y afectivos (diferentes tipos de emociones) (Atri y Zetune, 2006). De acuerdo con Westley y Epstein, los pasos que involucra son: la identificación del problema, comunicación del problema a la persona adecuada, implementación de alternativas de acción, puesta en marcha, verificación y evaluación de la acción (citados en Atri y Zetune, 2006). 
b. Comunicación: Hace alusión a la precisión del contenido de la información y la forma en que se intercambia y se clasifica en instrumental, afectiva y solución de problemas; implica cuatro estilos de comunicación como; clara y directa, clara e indirecta, confusa y directa, confusa e indirecta (Atri y Zetune, 2006).

c. Roles: Designan las funciones familiares de cada uno de sus integrantes, pueden ser instrumentales y afectivas; se subclasifican en necesarias y no necesarias; las funciones familiares necesarias son las de manejo central y son: 1) manutención económica, 2) afectividad y apoyo, 3) gratificación sexual adulta de los cónyuges, 4) desarrollo personal, y 5) crecimiento y satisfacción personal de cada uno de los miembros; por otro lado, de manera específica se encuentran las relacionadas con el sistema de manutención y administración, las cuales son: toma de decisiones, límites, control de conducta, economía doméstica, higiene física y mental, asignación de roles y revisión de roles. (Atri y Zetune, 2006).

d. Involucramiento afectivo: Hace alusión al nivel en que la familia demuestra interés y valora las actividades de cada miembro, así como la capacidad de expresar emociones con duración e intensidad razonables, implica tanto la calidad como la cantidad; es cuantitativo y/o cualitativo con seis tipos de involucramiento: 1) ausencia de involucramiento (falta interés en las actividades o el bienestar de los demás), 2) involucramiento desprovisto de afecto (el interés está centrado en el aspecto intelectual y no en los sentimientos), 3) involucramiento narcisista (se muestra interés en el otro sólo si implica favorecerse a sí mismo), 4) empatía (manifestación de interés auténtico en otro), 5) Sobreinvolucramiento (exagerado interés: sobreprotección e intrusión), y 6) simbiosis (interés patológico sin establecer límites que lo diferencien de la otra persona) (Atri y Zetune, 2006). 
e. Respuestas afectivas: Se refiere a cómo la familia responde con sentimientos apropiados en calidad y cantidad, va desde la no respuesta hasta la respuesta exagerada (Atri y Zetune, 2006).

f. Control de conducta: Se centra en los patrones familiares para manejar el comportamiento en situaciones específicas, negociar y cambiar; incluye aquellas que involucran peligro físico, para afrontar necesidades biopsicosociales e instintivas o para socializar intra e inter familiar; en este sentido las familias pueden desarrollar cuatro patrones de control para la conducta: rígido, flexible, laissez-faire (dejar hacer) y control de conducta caótico (inconsistente y no pertinente) (Atri y Zetune, 2006).

\section{Fenomenología Psicológica}

La fenomenología psicológica tiene como fundador a Husserl en la década de 1920. Figueroa (2008) de manera muy clara y concreta realiza una descripción de sus características e inicia señalando que el autor la conceptualiza como “(...) la relación íntima entre fenomenología como ciencia filosófica estricta y fenomenología como ciencia empírica de lo psíquico" (p. 228). Asimismo, señala que es un gran esfuerzo intelectual y científico al reducir los fenómenos que se muestran en la cotidianidad del mundo, de manera muy concreta plasma las siguientes características definitorias: 1) A priori: se ciñe principalmente a la vida psicológica. 2) Eidética: Tiene como finalidad las necesidades y generalidades de la conciencia y los fenómenos conscientes. 3) Intuición: Es la fuente del a priori, son visones inmediatas, que mediante su análisis se obtienen determinaciones de la esencia de lo visto. 4) Descripción: No pre-supone nada, se ajusta a lo estrictamente visto, representándolo en expresiones claras, completas y unívocas. 5) Intencional: Carácter básico del ser psíquico y 
fenomenológica se permanece en el mundo real y objetivo.

En esta postura, la interpretación juega un papel fundamental, Moustaka señala que la fenomenología psicológica está centrada en las interpretaciones del investigador de acuerdo con las experiencias de los participantes (citado en Creswell, 2007). Cuestión que fue trabajada como tal en esta investigación cuyo objeto de estudio fue el funcionamiento familiar en familias con padre migrante.

\section{Fenomenología Psicológica del Funcionamiento Familiar}

México es uno de los principales países con alto índice de migrantes hacia los Estados Unidos de Norteamérica, destacándose el Estado de México, de manera concreta el Municipio de Tonatico. Tradicionalmente es el padre el que migra, lo cual representa que la esposa y madre se quedé al frente del hogar, obligando a un ajuste en el funcionamiento familiar.

Partiendo de la idea que una familia funciona de determinada manera con sus elementos habituales cotidianos y cambia cuando uno de ellos abandona el núcleo, en esta investigación, a través del discurso obtenido por medio del grupo focal y la narrativa, nos acercamos a la subjetividad y a cómo experimentan el funcionamiento familiar madres de familia cuando su pareja migró a EE. UU. y cuál fue el papel del contexto que estaban inmersas, todo esto con la finalidad de comprender el objeto estudio. 


\section{Método}

\section{Diseño}

En esta investigación utilizamos el diseño fenomenológico psicológico porque a través del discurso podemos acercarnos a la subjetividad de las participantes, asimismo, permite respetar las asociaciones que las personas hacen de sus propias vivencias (Martínez, 2006). Para Salgado (2007) dan respuesta a la pregunta: “¿Cuál es el significado, estructura y esencia de una experiencia vivida por una persona (individual), grupo (grupal) o comunidad (colectiva) respecto de un fenómeno?” (p. 73).

Otras premisas que permiten el uso de este diseño son las señaladas por Creswell, Mertens y Álvarez-Gayou (citados en Hernández, Fernández y Baptista, 2014, pp. 493-494) son las siguientes:

- Se pretende describir y entender los fenómenos desde el punto de vista de cada participante y desde la perspectiva construida colectivamente.

- Se basa en el análisis del discurso y temas, así como en la búsqueda de posibles significados.

- El investigador confía en la intuición, imaginación y en las estructuras universales para lograr aprender las experiencias de los participantes.

- El investigador contextualiza las experiencias en términos de su temporalidad (momento en que sucedieron), espacio (lugar en el cual ocurrieron), corporalidad (las personas que la vivieron) y el contexto relacional (los lazos que se generaron durante la experiencia. 
Este diseño nos permite acercamos a la percepción del funcionamiento familiar de diez madres de familia que se han quedado al frente de su familia cuando su esposo ha migrado a EE. UU.

\section{Participantes}

Para realizar el estudio, trabajamos con 10 mujeres, los criterios de inclusión que definimos fueron: que su esposo estuviera en situación de migrante en EE. UU., que fueran amas de casa dependientes de las remesas económicas, que estuvieran o hubieran criado hijos, que su lugar de residencia fuera en el municipio de Tonatico, Estado de México.

Consideramos al varón como migrante porque de acuerdo con datos censales del INEGI (2010), la migración internacional es predominantemente masculina, ya que entre 2005-2010, de 1.1 millones que salieron del país, sólo una cuarta parte eran mujeres. Asimismo, el organismo indicó que el principal destino de migración fue EE. UU. (88.9\% del total de la población que durante este periodo salió del país) y es el Estado de México, uno de los que refleja altas tasas de migración en proporción con el número de habitantes, ocupando el cuarto lugar, ya que de cada 100 migrantes internacionales, 89 de ellos se fueron precisamente a ese país.

Para contar con el total de las participantes, se empleó la técnica de bola de nieve, para ello, primero detectamos a una persona que reuniera los criterios y pudiera contactarnos con otras participantes.

Las características de las participantes en cuanto a edad, oscilo entre 43 y 60 años. El tiempo de ausencia de la pareja por migración fue como mínimo de 8 años y máximo de 30. El número de hijos oscilo entre 3 y 7 (véase tabla 1 ). 


\section{Técnicas de Obtención de Información}

Las técnicas que utilizamos fueron el grupo focal y la narrativa, ambas permitieron la triangulación metodológica y de datos. Ambas se encuentran en correspondencia con el tipo de diseño, es decir, permite que entendamos el fenómeno de la migración desde una perspectiva individual y colectiva.

Consideramos el grupo focal porque la temática de investigación corresponde a un fenómeno social que permite la recolección de la información en un solo momento, además es posible favorecer el diálogo con las participantes y el sentimiento de acompañamiento con otras mujeres en las mismas circunstancias, situación clave en la obtención de los hallazgos. De hecho, Álvarez-Gayou (2009) menciona, esta técnica tiene la finalidad de favorecer el diálogo sobre un tema u objeto de investigación.

En cuanto a la narrativa, como técnica individual, permitió que las participantes se sintieran en libertad de expresar aquello que consideraban que no podían decir a la luz del grupo, lo cual no fue difícil de lograr. La ventaja de usar esta técnica radica en que las personas hablan sobre experiencias sobre algún tema de sus vidas, principalmente aquellas en las que han tenido una separación o conflicto entre un ideal y la realidad. (Álvarez-Gayou, 2009). Tanto el grupo focal como la narrativa las basamos en las categorías propuestas para el funcionamiento familiar.

Otro tipo de triangulación que utilizamos fue la de investigadores, que consistió en que les proporcionamos a expertos la guía de tópicos del grupo focal y de la narrativa con la finalidad de que fueran revisadas en cuanto a estructura y congruencia con las categorías planteadas. Cabe señalar que fueron tres investigadores en el área de la psicología, poseen con grado de doctor y son expertos en la temática. De esta forma logramos tener una guía de tópicos que fuera clara para nuestras participantes. 
Una vez localizadas e invitadas a todas las participantes de la investigación, les informamos sobre el anonimato de su identidad y el resguardo de su nombre original cambiándolo por uno ficticio, indicamos la confidencialidad de la información y su uso con fines académicos, les pedimos autorización para ser grabadas en audio. Todas estas consideraciones las plasmamos en una carta de consentimiento informado.

Para llevar a cabo la técnica de entrevista las sesiones fueron moderadas por nosotros de acuerdo con la guía de tópicos, propiciamos que se pudieran expresar libremente. La duración fue de tres horas en una sesión llevada a cabo en el turno vespertino, grabamos con audio los discursos, además cuidamos que el espacio físico tuviera suficiente luz y ventilación para establecer un ambiente de confianza.

En cuanto a la narrativa, la llevamos a cabo otorgándoles a las participantes papel y lápiz para que por medio de preguntas guía, escribieran desde su percepción sobre el funcionamiento familiar que prevaleció cuando su pareja marchó. Tuvo una duración en promedio de 30 minutos.

Para estructurar los resultados consideramos las categorías previamente conceptualizadas para el eje temático de funcionamiento familiar, que dio lugar al surgimiento de 14 temas que a continuación se enuncian:

1. Estructura familiar

2. Resolución de problemas instrumentales

3. Resolución de problemas afectivos

4. Comunicación instrumental

5. Comunicación afectiva

6. Roles de control de conducta 
7. Roles centrados en los límites

8. Revisión de roles

9. Roles de afectividad y apoyo

10. Roles afectivos de gratificación sexual

11. Involucramiento afectivo

12. Respuestas afectivas

13. Control de conducta caótico en situaciones que involucran peligro físico

14. Control de conducta rígido en situaciones que requieren sociabilización

\section{Análisis}

Analizamos la información de acuerdo con la fenomenología psicológica, lo cual consideramos una ventaja, pues el diseño corresponde al mismo enfoque y permite tener hallazgos de manera estructurada y congruente metodológicamente. De acuerdo con la propuesta de Creswell (2007), una vez obtenida la información de las participantes, procedimos a llevar a cabo el análisis y elaborar las matrices en el procesador de textos Microsoft Office Word, siendo de la siguiente manera:

1. Organizamos los archivos de la información obtenida con las técnicas empleadas.

2. Revisamos cada uno de los discursos en el grupo focal y las narrativas, haciendo notas al margen que permitieran codificar la información de acuerdo con las categorías planteadas.

3. La horizontalización: de acuerdo con la información obtenida, remarcamos los enunciados más importantes para entender cómo las participantes experimentaron el funcionamiento familiar una vez que su pareja migró a EE.UU. 
4. Agrupación de significados: una vez seleccionados los enunciados, escribimos el significado formulado asociado y los agrupamos en temas.

5. La descripción textural: Describimos las experiencias de acuerdo con los enunciados y temas previamente planteados.

6. La descripción estructural: Describimos del contexto que influyó en como las participantes experimentaron la migración de la pareja.

7. La estructura esencial: Realizamos una descripción concreta compuesta con los elementos esenciales del fenómeno.

8. La información final la presentamos en tablas.

\section{Resultados}

De acuerdo con las categorías planteadas en esta investigación, de diez trascripciones literales del grupo focal y diez narrativas, obtuvimos 72 afirmaciones significativas con sus significados formulados (ver tabla 2), posteriormente realizamos los conglomerados temáticos (ver tabla 3). De los 14 temas obtenidos, 8 corresponden a aspectos instrumentales $(1,2,4,6,7,8,13,14)$ y 6 afectivos $(3,5,9,10,11,12)$. Se presentan a continuación.

Tema 1. La estructura familiar se mantiene: 3

Tema 2. Resolución eficaz de problemas instrumentales: 7

Tema 3. Resolución de problemas afectivos: 7

Tema 4. Comunicación instrumental clara y directa: 3

Tema 5. Comunicación afectiva confusa e indirecta: 8

Tema 6. Roles centrados en el control de conducta: 7

Tema 7. Roles centrados en los límites: 2

Tema 8. Los roles se revisan: 4 
Tema 9. Búsqueda de roles de afectividad y apoyo: 3

Tema 10. Roles afectivos de gratificación sexual adulta ausentes: 5

Tema 11. Involucramiento afectivo escaso: 7

Tema 12. Respuestas afectivas: 3

Tema 13. Control de conducta caótico en situaciones que involucran peligro físico: 6

Tema 14. Control de conducta rígido en situaciones que requieren sociabilización: 7

\section{Tema 1. La Estructura Familiar se Mantiene}

Sentimientos iniciales de que la familia quedó fragmentada fue expresado por las participantes cuando su pareja migró. Sin embargo, no significó disolución, más bien una huella de ausencia, como lo vivió Josefina, "Es como si a tu familia la rompen, porque antes estaba completa", “al mismo tiempo Nancy señaló: "Es muy raro, se nos rompe la familia porque ya no lo tengo todos los días, pero sigue siendo mi esposo y el padre de mis hijos... no sé cómo explicar”. Aferración para mantener a los miembros unidos fue la respuesta al sentimiento inicial: "no estará su presencia, pero sigue estando ahí... es lo que he dicho siempre" (Norma). Lo afectivo se sobrepuso en la distancia y en tiempo, el padre es percibido como un miembro de la familia irremplazable, sentían que continuaba siendo su pareja y padre de sus hijos. Situación que se asocia a que el vínculo matrimonial no fue disuelto, tal como lo refirió Rosa, "Digamos que cuando él se va, cómo decirlo, seguimos siendo una familia, no junta separada, pero familia al fin y al cabo".

\section{Tema 2. Resolución Eficaz de Problemas Instrumentales}

En los diez casos hubo gran preocupación y presión emocional por las dificultades económicas para lograr que el esposo migrara, como mencionó Guadalupe "Por las noches 
no dormía, me volteaba para un lado y para el otro, piense y piense, que no teníamos ya dinero, que cómo le íbamos hacer no solo para comer, también para la casa, la escuela de los niños".

Fue común el endeudamiento o el patrimonio agotado (venta de terrenos y/o cosechas), aún después de la partida y hasta la llegada de las primeras remesas, tuvieron el apoyo de la familia de manera temporal, al respecto Elizabeth señaló, "Desde que mi marido se fue, de esto ya tiene cinco años, primero me las veía duras pásacar adelante a los chamacos, todo el dinero que teníamos fue pa'que el pudiera irse, pero nos quedamos sin nada y mi mamá es quien luego me traía el plato de frijoles para todos”.

Es claro que mejoró el poder adquisitivo de las familias, lo cual se reflejó en contar con una vivienda digna, "Mi casita era de tablas, con mi viejo por allá no tendría esta casota que ahora tenemos” (Emelia). También mejoró la alimentación, como sucedió a Nancy, “Ahora comemos mejor, carne, leche, manzanas, mis hijos ya comen de todo, antes no, antes era mucha la carestía".

\section{Tema 3. Resolución de Problemas Afectivos}

Sentirse solas y desamparadas fue el sentimiento común con la ausencia de su pareja, “... es como si le arrancaran a uno el alma, el corazón, uno sabe que nada volverá a ser igual... lo sabía porque vi uno desde niña a otras señoras ya mayores que han tenido la misma experiencia" (Laura).

Otras problemáticas aunadas, fueron; el hecho de no gozar independencia económica en su totalidad, pues su pareja delegó a su propio padre y/o hermano esta tarea, situación prevaleció a través del tiempo generando malestar, para Rosa, "si, si, si, fueron indicaciones de él, que es lo más peor, él que le dio los derechos de meterse a su papá en nuestra vida”. 
El enfrentamiento con la familia política fue inminente, suegros y cuñados conjeturaron que tenían derechos y obligaciones con ellas, surgieron entonces loas riñas y los desencuentros, como se refleja en la siguiente expresión “¡Pues ahora sí!, me dije, pues todos quieren mandar en mi casa pensé, como no está mi viejo... me ven como una mujer sola, que pueden pasar encima de mi... ya viene su hermano o hermana a decirme que hacer, pus no señor, no... los problemas los resolvemos nosotros como familia... les guste o no les guste" (Emelia).

Por otro lado, respecto a los hijos, hubo sentimientos de pérdida de autoridad y preocupación por la crianza, en lo cual contribuyó el autopercibirse como mujer sola y pensar que socialmente era vista así, no obstante lucharon por imponerse como jefas de familia, como en el caso de Josefina, "Quedarse sola es muy, muy feo, usted sabe que las mujeres perdemos más cuando nos quedamos solas, nos ven como que ya no valemos sin nuestros maridos".

\section{Tema 4. Comunicación Instrumental Clara y Directa}

Las participante de manera continua están inconformes porque la comunicación se concretó a girar en torno a la vida cotidiana del hogar, y a través del tiempo ha sido por vía telefónica y correo postal; si bien pareciera que es un punto a favor, emocionalmente no fue del todo satisfactorio, como señaló Isabel, “Con dinero muchos problemas se resuelven, pero eso no lo es todo en la vida, que ayuda mucho nadie lo niega, pero como que uno necesita más que eso".

Los temas que principalmente trataban era sobre los hijos; durante su infancia sobre la crianza y cuidado (salud, comportamiento cotidiano, amistades, estudio), cuando crecieron, sobre su proyecto de vida (pareja, trabajo, estudio), Hortensia comentó, "De los 
enfermaban y me alcanzaba para el doctor... cuando ellos crecen ya no es lo mismo, ahora es ver si están haciendo algo bueno con su vida”.

Otro tema igual de frecuente fue la distribución de las remesas económicas, que eran para el hogar y en las actividades agropecuarias y de agricultura de acuerdo con la temporada, como narró Isabel, “Con el tiempo eso cambió, ya solo era, que cuida al becerro, que el maíz no se te eche a perder".

\section{Tema 5. Comunicación Afectiva Confusa e Indirecta}

Desazón ante una comunicación carente de afecto es lo que expresaron las madres de familia, "Me faltó más cariñito cuando me hablaba o me escribía, me falta todavía..." (Hortensia), "Estando aquí parecía estatua, en la distancia, fue peor" (Nancy). Las expresiones no eran claras, “Cuando llamaba, me decía al final cuídate que haces falta, no entendía si a él o a los niños, o bueno, a todos... sigo sin saber lo que quería decir" (Emelia).

Consideran que la presencia física de la pareja permitía mayor cercanía afectiva, con el tiempo se diluyó, quedaron al margen como esposas, añoran el interés en ellas, no se encuentran satisfechas con la forma en que han llevado la relación, sin embargo con el tiempo se han resignado, como Isabel lo mostró, “Cuando recién se fue, si hablaba casi a diario, a veces llorábamos...con el tiempo eso cambió (...) Yo creo que el amor se va perdiendo, somos como hermanos, por eso hemos durado tanto" (Isabel).

Un aspecto común fue que se centraron en los recursos y en las añoranzas del lugar natal., los platillos que consumirán a su regreso, los planes en torno a la casa familiar, las actividades recreativas que realizarán, como dijo Norma, "Siempre me decía, cuando vuelva me harás unos nopalitos, frijoles, salsa de molcajete". 


\section{Tema 6. Roles Centrados en el Control de Conducta}

Una constante en esta categoría fue la preocupación y desgaste emocional por controlar la conducta, primero de ellas hacia los hijos y posteriormente vivir el control de su pareja, "El estar pendiente de los hijos es una tarea que no acaba, no acaba nunca, una mujer se las ve duras sola, tiene que saber qué hacen los hijos aunque tengas mil preocupaciones" (Elizabeth).

Respecto a los hijos, se presentó esfuerzo constante para posicionarse como jefas de familia y hacer cumplir las normas y reglas del hogar, ya que inicialmente con la ausencia del padre, no fueron vistas por los hijos como una figura de autoridad, fue una tarea difícil principalmente con los hijos varones como relató Laura, "Mis hijos, los hombres, se pusieron rebeldes, empezaron a desobedecerme, faltarme al respeto contestándome, vaya pues, querían hacer lo que quisieran... ¿cómo lo solucioné?, me tuve que cargar de valor y les daba duro, para que obedecieran".

Por otro lado, los esposos se apoyan en su familia para tener control de las participantes, motivo por el cual ellas reaccionan con enojo y prefieren la ausencia del cónyuge, dos participantes refirieron: "Le tengo que pedir permiso para ir al doctor, casi casi para comprar la comida...está mal decirlo, pero ya me acostumbré a que no esté” (Guadalupe). Por su parte Nancy comentó: “Mi cuñado... él es el que me vigila...las noticias llegan hasta el norte, hasta allá se sabe si uno se porta bien o mal... para que dar de hablar".

\section{Tema 7. Roles Centrados en los Límites}

Por otro lado, disgusto y rechazo manifiestan las mujeres participantes hacia la intromisión de la familia política en la vida cotidiana y económica, como mencionó Nancy, “siempre quiere estar aquí, si no es mi suegro, mi cuñado, espiando lo que hacemos, lo que 
en tu familia, no termina bien" (Nancy)

Esta situación llevó a la familia del migrante a que los límites y la autoridad se tornaran difusos con los hijos, como lo vivió Josefina, "Si yo hubiera estado sola, lo que se dice sola, hubiera sido más fácil todo, pero como mi suegro intervenía a cada rato, se quería meter todo el tiempo en cómo criaba y educaba a los niños, todo fue más difícil para mí” (Josefina). La madre se posiciona y toma el rol de imponerse ante su familia política y como figura de autoridad en su propio hogar, "No del todo he logrado sacar a mis cuñados de la casa... tuve que pensar cómo le hacía, lo mejor fue ya no invitarlos a las fiestas de mis hijos, así se fueron saliendo un poco" (Isabel)

\section{Tema 8. Los Roles se Revisan}

La revisión de roles fue la medida continua que implementaron las mujeres y les hizo sentir más satisfechas y tranquilas con su labor cotidiana, aunque por otro lado desgastante, como señaló Rosa, "Checo todavía lo que hace cada uno de mis hijos en mi casa, si a uno le tocan los animales, sigo checando que lo hayan hecho... si me canso, me duele todo, pero estoy más tranquila" (Elizabeth).

Lo que es claro, es que las madres se vieron obligadas a atribuir a los hijos asumen nuevas tareas con mayor responsabilidad: "Mis niñas desde bien chiquitas me ayudaron, les hacían el atolito a sus hermanitos, y cuando él venía y me embarazaba y luego se iba, no había quien me cuidara, eran ellas que lavaban los trastes con una cubetita dentro del cuarto" (Isabel).

La ausencia del padre obligó a una redistribución de tareas en el hogar, posteriormente con sus llegadas y partidas, forzaba a todos los miembros a reacomodarse. Guadalupe narró, 
"Cuando él está allá, todo va bien aquí... pero cuando llega, tengo que hacerme a un lado, porque llega a mandar, le tengo que pedir permiso para ir al doctor, casi casi para comprar la comida...está mal decirlo, pero ya me acostumbré a que no esté".

Por otro lado, se observó un esfuerzo constante por señalar la autoridad del padre: "Han pasado muchos niños y a él lo tienen que seguir viendo como lo que es su padre, el que mantiene la casa y tienen todo el derecho de llegar a mandarnos a todos" (Emelia). "El marido es el marido, nos guste o no, de lejitos o de cerquitas, es el jefe de una casa, le guste a quien le guste" (Rosa).

\section{Tema 9. Búsqueda de Roles de Afectividad y Apoyo}

El sufrimiento continuo y permanente por la ausencia de la pareja es sentida por las mujeres, "se resigna uno a que no esté el marido... pero no quiere decir que ya no duela, eso duele siempre, porque siempre se van otra vez" (Hortensia). Emelia lo vivió similar, "Si los hijos no salen buenos, ahora sí que estoy perdida, sin cariño de nadie me sentiría triste, ya tengo suficiente sin mi compañero".

En ausencia de afecto y apoyo, buscan el apoyo en la familia de origen, así como nuevas amistades que les ayuden a mitigar sus sentimientos, como en el caso de Josefina, "Me sentía sola, como mi viejo se enojaba, casi no hablaba con nadie, de manera emergente empecé a buscar con quien hablar, sino lo hacía me volvía loca. También Guadalupe señaló, "A mi edad ya tengo amigas, antes no tenía, ya vi que son necesarias, a veces te entienden mejor que los hijos" (Norma). 
Tema 10. Roles Afectivos de Gratificación Sexual Adulta Ausentes

La gratificación sexual en las mujeres participantes es carente, viven en constante añoranza por vivirse como mujeres, es decir, se extraña el acercamiento físico con la pareja. Con la migración, perdieron pareja y libertad, su vida sexual se condicionó a las llegadas y partidas del esposo. Isabel dijo, “A mí me hace mucha falta él, es como si una dejara de ser mujer cuando se va y vuelvo una a serlo de nuevo cuando vuelve... a nadie se le ocurre pensar que uno necesita un abrazo, una mano cariñosa... y así se van pasando los años hasta que a uno se le olvida esa necesidad de ser mujer, de tener pues, relaciones”.

Las largas ausencias del varón propician el acoso de hombres de la comunidad, provocando la crítica social y familiar, creando conflictos de pareja que se reflejaron en la disminución de remesas como castigo, no obstante, defendieron un papel de mujeres fieles a sus esposos. Emelia relata su experiencia, “... muchas veces me han propuesto cosas... sólo pasear... me ven sola los hombres... ni lo pienso, sólo imaginarme que por eso ya no me dará para mis hijos, sus estudios, lo pienso bien, me digo... eso no lo hace una mujer decente... llegué a tener problemas, me castigó mandándome poco dinero, según él, por si me lo gastaba con otra persona".

Como una medida de protección ante esta situación, las mujeres buscan apoyo de los varones de su familia de origen, como lo hizo josefina, "Una vez un viejito me dijo que nos juntáramos, que su esposa había muerto y ocupaba quien le diera de comer, le lavara y le planchara, primero me dijo: si su marido anda en el norte, ya no lo espere, goce la vida, disfrútela, tuve que decirle a mi hermano para que lo calmara". 
Tema 11. Involucramiento Afectivo Escaso

Ausencia de afecto y por ende tristeza, añoranza, sentimientos de vacío y soledad y resignación es lo que caracteriza el involucramiento afectivo de la familia, Rosa dijo, "Un hueco es lo que siento todavía, hueco que no se llena”.

Los hijos también lo sienten, de acuerdo con lo dicho por Emelia, "Veo que los muchachos si ya están bien, ya salieron adelante... pero vivían tristes, se les veía en su carita, a mí me dolía mucho, mucho... quisiera llenarles ese vacío, pero sé que no será así, un padre es un padre... aunque yo creo que yo sufría todavía más, tenía que cargar con mi pena, más la de ellos".

El periodo en que las participantes extrañaron a su pareja en mayor medida fue durante el primer año, cuando se presentaron los aniversarios a celebrar y las fiestas tradicionales, como lo vivió Guadalupe, “Lo más, más duro, es siempre el primer año, como cuando se muere alguien también, es algo parecido...pasar las fiestas de Navidad, o el día del padre, los cumpleaños, se les extraña muchísimo"

Sienten que el afecto como pareja se diluyó y que tiempo y la distancia fue el protagonista de esta situación: "En un principio sentía como que él me quería, como que me extrañaba, fueron pasando los días y ahora ya no siento eso, siento que solo nos ve como una obligación, como diciendo, ya cumplí mandándoles, ya vean por ustedes” (Laura). 


\section{Tema 12. Respuestas Afectivas}

Una pérdida irreparable y permanente es la forma en que atribuyeron las mujeres la partida de su pareja, se percibe al esposo como un compañero insustituible "No hay cariño igual que el de la pareja, el amor es distinto con cada persona de la familia, con lo hijos es distinto, pero el del viejito ya no se recuera nunca cuando se va para el otro lado" (Josefina).

Sentimientos de enfrentar la vida cotidiana solas, "Lo extrañé mucho, mucho, dicen por ahí que la pareja es a veces hasta más importante que los hijos, pues él, es el compañero... los hijos tarde o temprano se van, quien se queda son ellos, los maridos” (Rosa).

Las redes de apoyo son vitales para mitigar los sentimientos de pérdida, como lo hizo Elizabeth, “Ahora para que ya no estar triste, mejor voy y me confieso con el padrecito... me hecho el atole con la comadre, lloro, pero ya no dejé que mis hijos me vieran tanto".

\section{Tema 13. Control de Conducta Caótico en Situaciones que Involucran Peligro Físico}

Los conflictos empezaron con la ausencia del padre y fueron en aumento, las normas del hogar dejaron de tener efecto en los hijos cuando el padre migró, la preocupación principal fue el resguardo de su integridad física, refirió Laura "Cuando mis hijos no me obedecían lo que más me preocupaba es que estuvieran bien, que no les pasara nada porque ya no tenían a su papá que lo cuidara”.

Surge la lucha con los menores por controlar su conducta, ya que al ir creciendo respetaron menos a la madre como figura de autoridad, Rosa mencionó, "Mi coco ha sido cuando mis hijos no quieren agarrar su camino, cuando se iban de borrachos, de vagos y no querían trabajar, esos eran mis dolores de cabeza".

El padre en la distancia intenta controlar la conducta de los menores, además las participantes acuden a la familia de origen y política. Nancy relató que, "Cuando se fue él, 
mi hijo mayor estaba más pequeño, nos unimos más, sin embargo ahora ya pasaron ocho años y es un jovencito, pero no quiere componerse, no quiere estudiar, ni trabajar, ni ayudarme en la casa... solo cuando le habla su papá se compone unos días y luego vuelve a lo mismo, pienso yo que necesita una mano fuerte... hasta a alguien que lo escuche... y no lo tiene".

\section{Tema 14. Control de Conducta Rígido en Situaciones que Requieren Sociabilización}

Antes y posterior a que el padre migrara, la demanda de las actividades en el hogar limitaron tanto para los hijos como para las madres las actividades recreativas, además que la gama de oportunidades en la comunidad era escaza, como narró Josefina, "Yo siempre estuve preocupada por darles de comer, lavar, planchar, los animales, que iba yo a estar pensando en llevarlos a un lado... como hoy, que ya los llevan que a fútbol o computación, antes ni había eso, daban clases de cocina y de otras cosas, me llamaba la atención, pero que iba yo a poder ir, mis hijos menos, ellos juagaban en la casa".

El control de conducta era rígido en situaciones que requerían sociabilización, pues la participación en fiestas comunitarias y religiosas se posponía la participación activa en ausencia del padre, en el caso de Hortensia dijo, “... salir lo que se dice salir, nunca lo hicimos, cuando estaba él, íbamos a dar una vuelta al zócalo cuando había fiesta del santo patrono, éramos mayordomos y teníamos que estar pendientes, desde que se fue para el otro lado, ya no participo, ocupan a la pareja completa, pero tampoco iba a la fiesta no podía sola con tanto chamacal... ahora salgo un poquito más".

De hecho, las fiestas y tradiciones del pueblo y de la cultura mexicana son condicionantes para las llegadas y partidas del jefe de familia, como lo refirió Guadalupe, "Mi esposo antes de que se fuera, era, bueno éramos pues mayordomos de la iglesia, cuando 
día de muertos".

Por otro lado, se crearon otros lugares, cuando salían a barrer el patio y pasaban las vecinas o cuando iban a la tiendita de la esquina a comprar algo y socializaban con: "Nunca fui de amigas, tengo a mis comadres, y todas las mañanas platico con mi vecina un ratito mientras barremos la entrada de la casa" (Guadalupe).

\section{Descripción Esencial del Funcionamiento Familiar}

La migración del jefe de familia desde la perspectiva de sus esposas, significó un proceso de ajuste de las diferentes áreas del funcionamiento familiar en la vida cotidiana, asimismo, obligó a cada uno de los integrantes a acomodos cognitivos y afectivos. Es la distancia, la ausencia física fue el elemento precursor de estos cambios.

En la estructura familiar está presente un esfuerzo por adaptarse a la nueva idea de familia, la cual dista de lo que se conoce y lo que se vive, es decir, las participantes mantienen el carácter biparental de su núcleo familiar desde un nivel afectivo, pero no funcional que es resultado de los largos periodos de ausencia. Hay una resistencia en general de visualizar a una familia segmentada.

En un primer momento la resolución de problemas fue de tipo instrumental, hubo claridad en ubicarlos y dar resolución eficaz, destacan los de índole económica debido a la presencia de pobreza antes y durante la decisión de marchar del padre. Esta situación causó preocupación constante hasta que mejoraron las condiciones de vida.

No se vivió de igual forma la resolución de problemas afectivos, pues estos iniciaron justo en el momento en que su pareja marchó, la falta de su presencia y convivencia minó la estabilidad emocional de las participantes. 
Respecto a la comunicación instrumental, fue clara y directa, centrada en los aspectos

básicos de la vida cotidiana de la familia (vivienda, alimento, vestido), no obstante, afectivamente no fue totalmente satisfactorio para las participantes

En este sentido, la comunicación afectiva fue para ellas confusa e indirecta, la distancia, la poca comunicación verbal y la falta de tecnología cuando el padre migró, fue una de las causas atribuibles a las deficiencias presentadas en esta área. La persistencia de esta situación, fue motivo de sentimientos de desánimo y pesadumbre.

En cuanto a los roles de control de conducta, fue de las madres hacia los hijos y del varón hacia su pareja respecto al sistema de manutención y administración del hogar. Fue urgente la necesidad de intervenir con sus hijos, pues se desestabilizaron con la ausencia del padre. Por otro lado, fue desagradable someterse a la vigilancia de su pareja en la distancia, producto de la desconfianza sobre su conducta.

Situación similar ocurrió en los roles centrados en los límites, nuevamente para las madres fue tarea primordial delimitar la conducta de los hijos. Asimismo, imponer límites a la intromisión de la familia política fue parte sustancial que vivieron con desagrado.

Por lo tanto, la revisión de roles fue parte del ajuste realizado, caracterizado por acciones concretas dentro del hogar que redistribuyeran las tareas a los miembros, involucrando a los hijos. Poner límites y revisar los roles fue para las jefas de familia una tarea exhaustiva.

En los roles, también la afectividad y apoyo estuvo presente, caracterizados por su ausencia debido a las largas separaciones con la pareja, por lo que buscaron otras fuentes de apoyo como familiares y amistades que las hicieron sentir más revitalizadas y reconfortadas. 
De manera similar, hubo ausencia de roles afectivo de gratificación sexual adulta, es

decir las participantes no se posicionan en un papel de esposas, sólo como madres, la necesidad del contacto afectivo y físico con su pareja es característico a lo largo de su vida.

El involucramiento afectivo escaso es la constante, se hace presente la búsqueda de afecto y acompañamiento, para mitigar la soledad, por lo que se manifiesta un sobreinvolucramiento con los hijos y la familia de origen.

Esto se refuerza con las respuestas afectivas, las cuales toman tintes más negativos que positivos, para las participantes no hay calidez y afecto, lo cual lo viven de manera solitaria.

El control de conducta caótico en situaciones que involucran peligro físico, se caracterizó por la resistencia de los hijos ante los nuevos límites y por la intromisión de la familia del cónyuge, generando desorientación tanto en ellos como en sus madres, quienes en corto plazo lograron toman el control de la situación.

Finalmente, existe también un control de conducta rígido en situaciones que requieren sociabilización, primero porque las oportunidades de llevar a cabo actividades recreativas son limitadas, condicionadas por las carencias propias del contexto rural, en segundo lugar, porque se limita a usos y costumbres, dejando en segundo plano la intencionalidad y motivación para sociabilizar en otros ámbitos, no obstante, las participantes demuestras satisfacción en esta categoría. 


\section{Discusión}

De acuerdo con los hallazgos en esta investigación, los motivos por los que los varones migraron, se relacionan con las premisas de Durand (2000), de historicidad, vecindad y masividad, y primordialmente de búsqueda de soluciones en respuesta a un contexto poco alentador para progresar económicamente (Agustín, 2004; INEGI, 2010, 2015). Esta situación lejos de detenerse, va en constante aumento en México (Martínez, 2017; Zúñiga, 2004; INEGI, 2015). También se observa en otros países en los cuales las condiciones sociales, económicas, políticas y ambientales son desfavorables para desarrollarse de manera integral.

En cuanto a cómo viven las participantes el funcionamiento familiar, es un proceso adaptativo y desgastante física y emocionalmente, tal como se observa en el tema 1 de estructura familiar, en el cual desde su percepción afectiva no se modifica, no obstante, es claro que con la partida del varón surge el cuestionamiento sobre la pertinencia de continuar denominando al núcleo como biparental. Consideramos que el término mejor atribuible es el de Palacios y Rodrigo (2014) en el que prevalece el proyecto vital que se tiene como familia. En cuanto a la relación de pareja, sería el de conyugalidad a distancia (Ariza y D’Aubeterre, citadas en García et al., 2011), ambas caracterizadas por el hecho de que la cohabitación queda en segundo plano. Indudablemente, por motivos de migración, las familias con madre al frente son comunes en la mayoría de los países latinoamericanos (Alcalde-Campos y Pávez, 2013).

Indiscutible es el impacto que tiene la ausencia del padre en la familia, para Estrada (2008), es un hecho profundo. “(...) el miembro o grupo familiar migrante tiene que reestructurar todas sus acciones para enfrentarse a una cotidianidad que se le presenta nueva 

modificar con el funcionamiento de la familia en sus distintas áreas.

Las relaciones familiares son armónicas en cuestiones instrumentales de la vida cotidiana, como se observó en el tema 2 (resolución eficaz de problemas instrumentales), tema 4 (comunicación instrumental clara y directa). Esto es favorable, como menciona Atri y Zetune (2006), están relacionados con los factores de protección del sistema familiar, favoreciendo así, su buen funcionamiento.

En resolución eficaz de problemas instrumentales (tema 2) se destacan los de índole económico, marcados por Elizaga y Macisco (1972) y Andrade et al. (2016), como el motivo principal por el que el padre migra en un intento por mejorar la economía familiar, lo cual es exitoso. La comunicación instrumental clara y directa (tema 4), primordialmente se llevó a cabo por medios tradicionales (correo postal y teléfono), lo cual no coincide con Sandoval y Guerra (2010) sobre el uso de las telecomunicaciones actuales. Esto se debe a que en la época en que los padres migraron, el acceso al uso de las tecnologías era sumamente limitado, no solo en su región, sino en todo México, forzando a tener una comunicación con la familia cada vez más concreta.

Vinculado con lo anterior, los roles y el control de conducta cobran fuerza en las participantes, es común la necesidad de mantener bajo vigilancia estos aspectos que dan estructura a la familia, esto se obtuvo en los temas 6 (control de conducta), 7 (roles centrados en los límites), 8 (los roles se revisan), 13 (control de conducta caótica) y 14 (control de conducta rígido).

En el control de conducta (tema 6) la madre se impone como jefa del hogar y se sostiene en su familia. Para López (2007) e Intervida (2004), el aumento de responsabilidades para la mujer y la búsqueda apoyo en otras personas, es común cuando el jefe de familia se encuentra 
límites (tema 7), en el cual las madres se esfuerzan por dar orden a los roles difusos y contrarrestar la intromisión de la familia política. Esto coincide con Del Ángel y Rebolledo (2009) quienes señalan que cuando la familia del migrante se encuentra bajo el cuidado de los varones, la mujer pierde su independencia.

La revisión de roles (tema 8) está presente y obliga a las participantes a su redistribución, hay mayor obligación de los hijos, sin embargo la limitante es que son susceptibles de modificación con los viajes intermitentes del padre. Al respecto, Martín (2007) señala que las madres que se quedan al frente de la familia cuando el padre migra, hacen que cada miembro cumpla con su papel, sin embargo, el reto mayor es la sobrecarga de éstos y el ajustarse a las llegadas y partidas del esposo.

Respecto al control de conducta, se considera caótico (tema 13) debido a la lucha continua de controlar a los hijos en situaciones que involucran peligro físico, para López (2007) esto tiene su raíz en el hecho de que una vez que el padre migra recae sobre las mujeres el cuidado y educación de los menores.

En situaciones que requieren sociabilización intrafamiliar (tema 14), fue rígido, ya que el hecho de vivir en una comunidad como Tonatico con características aún rurales, limita las oportunidades de desarrollo educativo y recreativo. No obstante, aspectos como las tradiciones y celebraciones culturales cobran relevancia en la vida cotidiana, tanto para los migrantes como para las familias que se quedan, tal como es referido por Sandoval y Guerra (2010). Por otro lado, se mantuvo el mandato sin cuestionamiento de los padres hacia los hijos de marchar hacia EE. UU, para Sandoval y Guerra (2010) esto es migración cultural. 
La existencia de estos temas se explica en todos los casos, con la evidencia de que

quien se quedó al frente, fueron ellas. García et al. (2011), señala que cuando el cónyuge se va al Norte, las esposas de los migrantes se las tienen que arreglar en la comunidad.

Por otro lado, la afectividad jugó un papel central en todas las participantes, lucha por hacerse valer como madres y esposas, frialdad afectiva, abandono, soledad y necesidad de acompañamiento fue el común en los temas 3 (resolución de problemas afectivos), 5 (comunicación afectiva confuso e indirecta), 9 (Búsqueda de afectividad y apoyo), 10 (roles afectivos de gratificación sexual adulta), 11 (involucramiento afectivo escaso) y 12 (respuestas afectivas). Si bien el buen funcionamiento de las áreas instrumentales coadyuva a aminorar el sentimiento de pérdida, no se vive así de manera interna.

En Resolución de problemas afectivos (tema 3), los más frecuentes se relacionan con la familia política y su intromisión en la vida cotidiana por indicaciones del migrante. Estos hallazgos no son aislados, se han reportado de manera similar por Del Ángel y Rebolledo (2009) en Veracruz, México, quienes encontraron que cuando el jefe de familia migra, hay prevalencia de los roles alusivos a su línea, jugando las mujeres un papel tradicional, sin independencia económica y bajo la resguardo económico y moral de la familia política, y a expensas de la voluntad del varón. Para Caballero et al. (2008), se tiende a buscar la protección y el apoyo de la familia política o de origen.

Por otro lado, en comunicación afectiva caracterizada por ser confusa e indirecta (tema 5) se observa poco emocional y centrada en el lugar de origen. Desde la perspectiva de Zanatta (2013), esto no es lo idóneo para una familia, pues una buena comunicación es fundamental para el bienestar de los miembros; en este caso, para la mujer que aguarda. Asimismo, el hecho de ser estar centrado en el país de origen, coincide con Casasa (2008), Falicov (2001) y García et al. (2011), quienes enfatizan que cuando hay migración, toma 
dejó

En los roles de afectividad y apoyo (tema 9), existen sentimientos de soledad, sufrimiento de los hijos y la creencia de ser percibida como mujer sola, son compatibles con la mirada de López (2007) sobre los efectos devastadores que conlleva este suceso vital. De acuerdo con Caballero (2008), esto es normal cuando la ausencia del padre se prolonga por causas de la migración.

Similar a esta situación se encuentra el rol afectivo de gratificación sexual adulta (tema 10), que presenta gran impacto en las mujeres, la ausencia de la pareja desemboca en un sentimiento de carencia es continua. Para Atri y Zetune (2006), si bien cubrir los roles de manutención económica favorece el desarrollo personal, no es suficiente cuando están ausentes la afectividad, el apoyo y la gratificación sexual del cónyuge, ya que se merma el crecimiento y satisfacción personal. Es necesario entonces reacomodarse y utilizar sus recursos emocionales para adaptarse a la ausencia afectiva (Becerra, 2014; Palacios et al., 2014).

El involucramiento afectivo escaso (tema 11) y las respuestas afectivas (tema 12) tienen en común que también se viven con ausencia de afecto y sentimientos de tristeza y soledad permanentes. Esto se explica con el papel relevante que el padre tiene en la vida familiar (Palacios et al., 2014).

Este es uno de los roles sustanciales en las participantes y las que merman en mayor medida su estado emocional, motivo por el cual acuden afectivamente a otras fuentes, como la familia y amistades.

En este estudio no se reportan discrepancia entre las participantes, más bien coinciden con investigaciones previas (Caballero et al., 2008; Del Ángel y Rebolledo, 2009; García, et 
al., 2011; Intervida, 2004; López, 2007). Una posible explicación es que la migración internacional, independientemente del contexto posee características similares, al igual que las funciones centrales del núcleo familiar.

Por sí misma, la migración del padre de familia conlleva a un ajuste general del funcionamiento en la familia, motivo por el cual es preciso continuar indagando en los diversos contextos, no solo en México, sino en otros países latinoamericanos que también está presente de manera frecuente y con quienes tenemos grandes similitudes económicas, sociales y culturales.

Esta investigación se logró enfocar en un marco no positivista, como bien lo sugiere Membrillo et al. (2008). Con las técnicas empleadas se logró el acercamiento a la subjetividad de las participantes (Martínez, 2006; Álvarez-Gayou, 2009). Permitió comprender sus experiencias vividas en torno a la partida de la pareja (Salgado, 2007). No sin olvidar la rigurosidad metodológica propuesta por Figueroa (2008), Creswell (2007) y Hernández et al. (2014).

Los hallazgos de esta investigación confirman la pertinencia de utilizar la propuesta de funcionamiento familiar de Atri y Zetune (2006), la cual está basada en el modelo de McMaster, utilizado en una diversidad de investigaciones en las cuales se observa de manera consiste que las dimensiones son las mismas o con mínimas variaciones (Epstein, et al., 1983; González \& González, 2008; González, Zanatta \& Sánchez, 2011; Guadarrama, Márquez, Veytia, \& León, 2011; Zanatta, 2013; Plascencia, Eguiluz \& Osorio, 2016). Una de las mayores contribuciones radica en que describe la estructura, organización y patrones transaccionales de la unidad familiar. (Epstein, et al., 1978). De tal manera que es preciso señalar que los hallazgos de este estudio empatan congruentemente con la literatura existente sobre esta temática, no obstante, ante la migración cada vez más visible de mujeres y niños 
sus experiencias al atravesar de manera ilegal como grupos vulnerables y como éstas impactan la vida familiar.

\section{Conclusiones}

La migración es un fenómeno social en México que afecta de manera crónica y profunda a un gran número de familias mexicanas, especialmente de zonas rurales. En este estudio, su origen tiene que ver con condiciones de pobreza y desigualdad social que limita a la familia para tener una calidad de vida digna. Algunas conclusiones derivadas de este estudio son:

El vínculo del matrimonio se mantiene indisoluble en el tiempo y en la distancia, hay cohabitación temporal de acuerdo con las llegadas y partidas, es decir, la presencia del padre es relativa.

La resolución de problemas giró en torno a tres aspectos con sus respectivos temas; instrumentales (dos temas), control de conducta (cinco temas) y afectivos (seis temas). El primero se relaciona con la vida cotidiana, el sistema de manutención y administración del hogar. El segundo con el funcionamiento interno de la vida familiar en torno a las acciones de cada uno de los miembros y el tercero a la vida afectiva, principalmente de las participantes.

Cabe señalar que la esposa y madre es la responsable principal del funcionamiento familiar cuando su pareja migra, tarea que no es fácil en una sociedad tradicional, como son las zonas rurales en México, caracterizadas por el papel subordinado de la mujer y con mayor desventaja social que los varones, si bien luchan para cambiar esta condición, la mayoría de las veces acatan a las normas impuestas, ambos casos son para ellas son desgastantes. 
Estos hallazgos reflejan que la figura del padre es ampliamente valorada, insuperable

para los miembros del sistema familiar, aunque poco afectiva, es entrañable para la pareja y los hijos. En su ausencia, los integrantes buscan nuevas formas de adaptación y funcionamiento, pues es un evento que fragiliza a la familia de forma general.

La migración hacia EE. UU. si bien tiene sus raíces en una necesidad económica, se ha hecho parte de la identidad cultural de los mexicanos.

Los hallazgos de esta investigación dan cuenta de cómo la migración del jefe de familia afecta el funcionamiento familiar y el papel relevante que tiene la esposa en el cuidado del hogar y los hijos, no obstante, constituye una limitante el haber trabajado solo en la región Centro de México, pues al ser un país multicultural los hallazgos no son susceptibles de ser generalizados para toda la población. Por otro lado, es preciso considerar que las parejas de las participantes con las que se realizó la investigación, migraron en su mayoría hace 10 años, motivo por el cual no es posible asegurar que actualmente se vive la migración del jefe de familia de la misma forma que la aquí encontrada, pues es muy claro que la migración es un proceso dinámico.

Se sugiere entonces, continuar en abundancia con los estudios sobre migración y familia en diferentes tiempos contextos en el campo en la psicología. 


\section{Referencias}

Agustín, L. (2004). Trabajar en la industria del sexo y otros tópicos migratorios. Madrid: Tercera Prensa.

Alcalde-Campos, R. \& Pávez, I. (2013). Infancia, familias monoparentales e inmigración Latinoamérica en Barcelona, España. Revista Latinoamericana de Ciencias Sociales, Niñez y Juventud, 11(1), 229-243.

Álvarez-Gayou, J. L. (2009). Cómo hacer investigación cualitativa, Fundamentos y metodología. Ciudad de México: Paidós.

Andrade, J. A., Alvis, L., Jiménez, L. K., Redondo, M. P. \& Rodríguez, L. (2016). Secuelas psicológicas de la guerra en mujeres forzadas a desplazarse. Revista Internacional de Psicología, 15(1), 1-62. https://doi.org/10.33670/18181023.v15i01.173

Atri y Zetune, R. (2006). Cuestionario de Evaluación del Funcionamiento Familiar (EFF).

En M. L. Velasco \& M. R. Luna (Eds.). Instrumentos de evaluación en terapia familiar y de pareja. (pp. 1-27). Ciudad de México: Pax.

Becerra, C. (15 de junio de 2014). La del padre, una figura en proceso de extinción. Periódico El Financiero. Recuperado de http://www.elfinanciero.com.mx/mas/enfoques/la-delpadre-una-figura-en-proceso-de-extincion.html

Caballero, M., Leyva-Flores, R., Ochoa Martín S.C., Zarco, A. \& Guerrero, C. (2008). Las mujeres que se quedan: migración e implicación en los procesos de búsqueda de atención de servicios de salud. Salud Pública, 50(3), 241-250. https://doi.org/10.1590/S0036-36342008000300008

Casasa, P. (2008). Migración e identidad cultural. Revista de Trabajo Social de la UNAM, $19,35-48$. 
Creswell, J. W. (2007). Qualitative inquiry \& research design. Choosing among five approaches. California: SAGE Publications.

Del Ángel, A. L. \& Rebolledo, A. (2009). Familia, remesas y redes sociales en torno a la migración de Veracruz central. Revista Estudios Fronterizos, 10(19), 9-48.

Durand, J. (2000). Tres premisas para entender y explicar la migración México-Estado Unidos. Relaciones. Estudios de historia y sociedad, XXI(83), 19-35. Recuperado de https://www.redalyc.org/pdf/137/13708302.pdf

Elizaga, C. \& Macisco, J. (1972). Migraciones internas: teoría, métodos y factores sociológicos. Santiago de Chile: Centro Latinoamericano de Demografía, Chile.

Epstein, N., Bishop, D. \& Levin, S. (1978). The McMaster of Family Functioning. Journal of Marital and Family Therapy, 4(4), 19-31. https://doi.org/10.1111/j.17520606.1978.tb00537.x

Epstein, N., Baldwin, L. \& Bishop, D. (1983). The McMaster of Family Assessment device. Journal of Marital and Family Therapy, 9(2), 171-180. https://doi.org/10.1111/j.1752-0606.1983.tb01497.x

Estrada, M. (2008). Diferencia que hace la diferencia. Migración y organización familiar. Revista Desacatos, 28, 89-100. Recuperado de http://www.scielo.org.mx/pdf/desacatos/n28/n28a7.pdf

Falicov, C. (5 de octubre de 2001). Migración, pérdida ambigua y rituales. VIII Congreso Nacional de Terapia Familiar de la Asociación Mexicana de Terapia Familiar y en Conferencia organizada por CEFYP. Buenos Aires, Argentina. Recuperado de http://www.redsistemica.com.ar/migracion2.htm 
Figueroa, G. (2008). La psicología fenomenológica de Husserl y la psicopatología. Revista

Chilena de Neuropsiquiatría, 46(3), 224-237. https://doi.org/10.4067/S0717$\underline{92272008000300008}$

García, M. D., Lozano, G., Luis, O. E. y Zavala, J. (2011). Familia y migración. En J. Moral, J. L. Valdez, N. I. González Arratia. (Coord.). Psicología y Salud. (pp. 253-276). Saltillo: Consorcio de Universidades Mexicanas.

González, C. M. \& González, S.I. (2008). Un enfoque para la evaluación del funcionamiento familiar. Revista Mexicana de Orientación Educativa, 6(15), 2-7. Recuperado de: http://pepsic.bvsalud.org/pdf/remo/v6n15/v6n15a02.pdf

González, V. J., Zanatta, E. y Sánchez, C. A. (2011). La construcción de los estilos identitarios en adolescentes y el tipo de funcionamiento familiar. Revista de Psicología de la Universidad Autónoma del Estado de México. Nueva Época, 21(1), 8-23.

Guadarrama, R., Márquez, O., Veytia, M. \& León, A. (2011). Funcionamiento familiar en estudiantes de nivel superior. Revista Electrónica de Psicología Iztacala, 14(2), 179192.

Recuperado de: http://www.iztacala.unam.mx/carreras/psicologia/psiclin/vol14num2/Vol14No2Art1 $\underline{0 . p d f}$

Hernández, R., Fernández, C. y Baptista, P. (2014). Metodología de la investigación (6 ${ }^{\mathrm{a}}$. Edición). Ciudad de México: McGraw Hill.

Intervida (14 de mayo de 2004). El fenómeno migratorio supone la desintegración del 36\% de las familias centroamericanas. Periódico El Mundo. Recuperado de http://www.elmundo.es/elmundo/2004/05/13/solidaridad/1084441162.html 
Instituto Nacional de Estadística y Geografía (2010). Estadísticas A propósito del día

internacional de la mujer. $\quad$ Recuperado de http://www.inegi.org.mx/saladeprensa/aproposito/2017/mujer2017_Nal.pdf

Instituto Nacional de Estadística y Geografía (2015). Estadísticas a propósito de día internacional del migrante (18 de diciembre) Recuperado de http://www.inegi.org.mx/saladeprensa/aproposito/2015/migrante0.pdf

López, G. (2007). Migración, mujeres y salud emocional. Decisio, 46-50. Recuperado de http://repositoriodigital.academica.mx/jspui/bitstream/987654321/21786/1/decisio1 8_saber8.pdf

Martín, C. (2007). Nuevas direcciones para estudios sobre familia y migraciones internacionales. Aldea Mundo, 11(22), 55-66. Recuperado de http://www.saber.ula.ve/bitstream/123456789/18230/2/articulo5.pdf

Martínez, M. (2006). Ciencia y arte en la metodología cualitativa. Ciudad de México: Trillas.

Martínez, T. (30 de enero de 2017). Entre 2015 y 2016, la mayor emigración de mexicanos en 5 años. Periódico el Financiero. Recuperado de http://www.elfinanciero.com.mx/economia/entre-2015-y-2016-la-mayoremigracion-de-mexicanos-en-anos.html

Membrillo, A. Fernández, M. Á., Quiroz, J. R. \& Rodríguez, J. L. (2008). Familia Introducción al estudio de sus elementos. Ciudad de México: ETM.

Palacios, J., Hidalgo, M. V. \& Moreno, M. C. (2014). Familia y vida cotidiana. En M. J. Rodrigo \& J. Palacios (Coords.), Familia y desarrollo humano (pp. 71-90). Madrid: Alianza Editorial. 
M. J. Rodrigo y J. Palacios (Coords.), Familia y desarrollo humano (pp. 25-44). Madrid: Alianza Editorial.

Plasencia, M. L., Eguiluz, L. L. \& Osorio, M. (2016). Relación entre la dinámica familiar y las fortalezas humanas. Journal of Behavior, Health \& Social Issues, 8(2), 1-8. http://dx.doi.org/10.1016/j.jbhsi.2016.11.00

Salgado, A. C. (2007). Investigación cualitativa: Diseños evaluación del rigor metodológico y retos. Liberabit, 13, 71-78.

Sandoval. E. A. \& Guerra, E. (2010). Migrantes e indígenas: acceso a la información en comunidades virtuales e interculturales. Málaga: Eumed. Recuperado de http://www.eumed.net/libros-

gratis/2010b/684/El\%20caso\%20de\%20estudio $\% 20$ Tonatico\%20Estado\%20de\%20Me $\underline{\text { xico.htm }}$

Sandoval, E. A., Román, R. P. \& Salas, R. (2013). Familia y migración. Ciudad de México: Universidad Autónoma del Estado de México-Porrúa.

Zanatta, E. (2013). El dispositivo familiar en la formación del estado de bienestar en adolescentes mexicanos. En J. A. Vírseda \& L. A. Oblitas (Coords.), Salud y familia ¿cómo obtener la salud conyugal y familiar? (pp. 85-104). Bogotá: Biblomedia.

Zúñiga, E. (2004). La nueva era de las migraciones, características de la migración internacional en México. Ciudad de México: CONAPO. 
Tabla 1

Características de las participantes

\begin{tabular}{cccc}
\hline Nombre ficticio & Edad & $\begin{array}{c}\text { Tiempo de migración de } \\
\text { la pareja }\end{array}$ & Número de hijos \\
\hline Guadalupe & 48 & 17 & 4 \\
Isabel & 52 & 22 & 6 \\
Rosa & 46 & 8 & 5 \\
Emelia & 49 & 12 & 3 \\
Laura & 55 & 15 & 6 \\
Josefina & 60 & 30 & 6 \\
Norma & 50 & 21 & 7 \\
Nancy & 43 & 8 & 4 \\
Elizabeth & 57 & 5 & 6 \\
Hortensia & 50 & 10 & 4 \\
\hline
\end{tabular}


Tabla 2

Afirmaciones significativas y significados formulados relacionados de las participantes

Afirmaciones significativas

1. Digamos que cuando él se va, cómo decirlo, seguimos siendo una familia, no junta separada, pero familia al fin y al cabo (Rosa).

2. Es muy raro, se nos rompe la familia porque ya no lo tengo todos los días, pero sigue siendo mi esposo y el padre de mis hijos...no sé cómo explicar (Nancy)

3. Seguimos siendo marido y mujer, recibimos la bendición de Dios y nos casamos por todas las leyes, estamos lejos pero nadie nos puede separar (Emelia)

4. Desde que mi marido se fue, de esto ya tiene cinco años, primero me las veía duras pa'sacar adelante a los chamacos, todo el dinero que teníamos fue pa'que el pudiera irse, pero nos quedamos sin nada y mi mamá es quien luego me traía el plato de frijoles para todos (Elizabeth).

5. Para que él se fuera de brasero, vendimos la cosecha se cebolla, los animales, y nos endeudamos, lo regresaron dos veces pero ya tiene su tiempecito allá (Guadalupe).

6. Dilatamos en reunir lo que ocupaba para irse, fuimos con el prestamista y los ahorros que teníamos los usamos, hasta que se le hizo (Laura).

7. Empecé a recibir dinero del otro lado, poquito pero si... pienso que vale la pena, como le digo... una cosa por otra, estamos solos, pero ya pasamos menos penurias (Elizabeth).
El padre está ausente pero se le sigue percibiendo como parte de la familia.

Aún en la distancia se mantiene la alianza del matrimonio.

Dificultades económicas para lograr que el esposo migre. El apoyo de la familia de origen está presente.

Se pierde el patrimonio con la partida del padre.

Hay endeudamiento para lograr que el esposo migre.

La carencia económica inicial, se compensa con el bienestar económico posterior. 
Afirmaciones significativas

Centro de Investigación sobre Desarrollo Humano y Sociedad

\section{Significados formulados}

8. Ahora comemos mejor, carne, leche, manzanas, mis hijos ya comen de todo, antes no, antes era mucha la carestía (Nancy).

9. No quiere decir que hay despilfarro, pero si, ya tenemos pa'comer, ya hay cositas que antes no había en la casa como jamón, cereal de ese de cajita, lujos pues (Hortensia).

10. Así que digamos que somos ricos, no, no, quisiéramos. Nos hemos hecho de esta casota gracias a que somos muy, muy ahorrativos (Norma).

11. La familia de él, se siente la autoridad, pero él tiene la culpa, tiene la culpa de todo, les dio permiso que de vinieran a mandarme, de quedarse con lo que mandaba, que porque soy mujer sola, ese fue el motivo (Emelia).

12. Mi cuñado es quien acapara todo mi dinero, es mi dinero, porque ¿acaso no soy yo la que cuida de sus hijos?, ¿acaso no es mi esposo? ¿acaso no me endrogué para que él se fuera? Hasta mi suegro se mete, dice que a una mujer no es buena administradora (Elizabeth).

13. ¡Pues ahora sí!, me dije, pues todos quieren mandar en mi casa pensé, como no está mi viejo... me ven como una mujer sola, que pueden pasar encima de mí (Emelia).

14. ¡Pues ahora sí!, me dije, pues todos quieren mandar en mi casa pensé, como no está mi viejo... me ven como una mujer sola, que pueden pasar encima de mi... ya viene su hermano o hermana a decirme que hacer, pus no señor, no... los problemas los resolvemos nosotros como familia... les guste o no les guste" (Emelia).
Mejora la alimentación de la familia con las primeras remesas recibidas.

Mejoró la situación financiera de la familia pero no hay exceso económico.

Se tiene acceso a alimentos fuera de la canasta básica.

La familia política adquiere la tutela de la familia de las participantes, con la autorización del migrante.

Inconformidad porque cuñados y suegros se hacen cargo de las finanzas de la familia del migrante.

Disgusta la intromisión de la familia política en la autoridad del hogar.

Lucha constante para imponerse como jefa de familia. 
Afirmaciones significativas Centro de Investigación sobre Desarrollo Humano y Sociedad

15. Los chamacos al principio bien, Se desestabilizan los hijos y la madre después se me querían subir a las barbas, toma el mando.

creían que yo no podía mandarlos y les dije que aquí mando yo, es mi casa y mando yo (Isabel).

16. Llevar sola la casa, no es fácil... era madre y padre... mis hijos me veían a veces débil. Era como si fuera una mujer sola, pero yo he tenido que agarrar carácter, coraje para enfrentarme a lo que viene, porque estoy sola, sola... como madre soltera" (Rosa).

17. Quedarse sola es muy, muy feo, usted sabe que las mujeres perdemos más cuando nos quedamos solas, nos ven como que ya no valemos sin nuestros maridos (Josefina).

18. Hoy en día hay mucho aparato para hablar al otro lado, el internet, el correo de computadora, el Face ese, pero antes puro teléfono y correo antigüito (Laura).

19. De los que más conversábamos era sobre los hijos, que si iban a la escuela, cómo iban, si se enfermaban y me alcanzaba para el doctor... cuando ellos crecen ya no es lo mismo, ahora es ver si están haciendo algo bueno con su vida (Hortensia).

20. Las primeras veces que le hablan a uno, nos hablábamos harto... se aguanta uno para no llorar... hasta que se va pasando...como dice el dicho: A todo se acostumbra uno, menos a no comer (Josefina)

21. Con el tiempo eso cambió, ya solo era, que cuida al becerro, que el maíz no se te eche a perder (Isabel).

Se autopercibe como mujer sola.

Percepción de que socialmente es vista como mujer sola, que la pareja otorga valor como mujer y esposa.

Modo de comunicación por teléfono y correo postal.

Comunicación inicial, centrada en los hijos, primero sobre su infancia y después en sus actividades como jóvenes y adultos.

Habituación a la comunicación escasa.

La comunicación se vuelve cada vez más concreta (centrada en la economía del hogar) y menos emocional. 


\begin{tabular}{l} 
Afirmaciones significativas \\
\hline 22. Cuando recién se fue, si hablaba \\
casi a diario, a veces llorábamos...con el \\
tiempo eso cambió (Isabel). \\
23. Yo creo que el amor se va \\
perdiendo, somos como hermanos, por \\
eso hemos durado tanto (Isabel). \\
24. Me decía cuando vaya pa'lla me \\
vas a hacer un molito, unos tamales, aquí \\
no hay picante como allá (Isabel).
\end{tabular}

25. Siempre me decía, cuando vuelva me harás unos nopalitos, frijoles, salsa de molcajete (Norma).

26. Me dice: ya vamos a tener dinero para salir a algún lado con la familia, con los niños, mi suegra (Isabel).

27. Cuando me escribía cartas, me decía cómo quería que fuera quedando la casa, un arco aquí, un corredor con macetas allá, siempre hablaba de todo lo que le iba hacer a la casa al regresar (Guadalupe).

28. Pues no me gusta, antes a mí me daba el dinero, que para la salida del niño, que para comprar semilla, ahora no, todo al hermano, él me va dando como se le da la gana para lo que es más importante y yo sólo veo y digo ¡hay mi dinero; (Nancy).

29. Mis hijos, los hombres, se pusieron rebeldes, empezaron a desobedecerme, faltarme al respeto contestándome, vaya pues, querían hacer lo que quisieran (Laura).

30. Una mujer nunca va a ser como el hombre en mandar, apenas no lo vieron cerca mis hijos y se me quisieron subir a las barbas (Nancy).
Comunicación que gradualmente es menos afectiva a través del tiempo.

Se extrañan los alimentos típicos del lugar de origen.

Se planea sobre alimentos que se consumirán al regresar al país natal.

Planes recreativos para el futuro.

Planes en torno a la casa familiar

La familia política como motivo de comunicación conflictiva.

Los hijos inicialmente no vieron a la madre como figura de autoridad.

Esfuerzo de la madre para imponerse como figura de autoridad. 


\section{Afirmaciones significativas}

31. ¿Cómo lo solucioné?, me tuve que cargar de valor y les daba duro, para que obedecieran" (Laura).

32. No hallaba cómo hacer que los chamacos entraran al huacal de nuevo, los miré y miré hasta que pensé que si me portaba como él iba hacerme obedecer, empecé a gritar, a mandarlos con harta fuerza y ya empezaron a caminar derechitos (Guadalupe).

33. No puedo hacer lo que yo quiera, no, por allá se sabe todo, lo bueno y lo malo que una hace, apenas se enteraba de cosas, y que no eran graves, me reclamaba bien feo, me regañaba (Laura).

34. Le tengo que pedir permiso para ir al doctor, casi casi para comprar la comida...está mal decirlo, pero ya me acostumbré a que no esté (Guadalupe).

35. Mi cuñado... él es el que me vigila...las noticias llegan hasta el norte, hasta allá se sabe si uno se porta bien o mal... para que dar de hablar (Nancy).

36. Si yo hubiera estado sola, lo que se dice sola, hubiera sido más fácil todo, pero como mi suegro intervenía a cada rato, se quería meter todo el tiempo en la educación, todo fue más difícil para mí (Josefina).

37. Mis hijos parecían loquitos, ya no sabían ni quien era quien, con eso de que venía un familiar y luego otro a querer mangonearnos, parecían vacas locas todos (Hortensia)

38. Mija me ayudaba, un día le tocaba a ella cuidar a sus hermanos y otro a mí, igual ir por ellos a la escuela (Laura).
El esposo en la distancia busca la forma de estar enterado de las acciones de la esposa.

El migrante mantiene el control con la esposa en la distancia.

Con el control del migrante en la distancia, la esposa prefiere su ausencia.

La familia política vigila la conducta de las participantes.

Intromisión de familia política que torna compleja la educación de los hijos.

Roles que se tornan difusos en cuanto a límites y autoridad con los hijos.

Redistribución de las tareas en el hogar. 
39. Cuando él está allá, todo va bien aquí... pero cuando llega, tengo que hacerme a un lado, porque llega a mandar (Guadalupe).

40. Mis niñas desde bien chiquitas me ayudaron, les hacían el atolito a sus hermanitos, y cuando él venía y me embarazaba y luego se iba, no había quien me cuidara, eran ellas que lavaban los trastes con una cubetita dentro del cuarto (Isabel).

41. El marido es el marido, nos guste o no, de lejitos o de cerquitas, es el jefe de una casa, le guste a quien le guste (Rosa)

42. Me sentía sola, como mi viejo se enojaba, casi no hablaba con nadie, de manera emergente empecé a buscar con quien hablar, sino lo hacía me volvía loca (Josefina).

43. Cuando él se fue, fue muy feo, estuve llorando ocho días, como que se murió alguien... bueno sabía que mi esposo seguiría siendo mi esposo, pero ahora de lejos....ahora sí que solo de nombre, pero dentro de mí es como si ya lo hubiera perdido...yo me decía por dentro, aguántate, es para mejorar...el sentimiento no pasa nunca, porque, si los pierdes...al final estás sola (Norma).

44. Para una mujer sola es muy difícil quedarse en un pueblo como este, tuve que arrimarme con mi familia para que me ayudaran a verme acompañada (Laura).

45. A mí me hace mucha falta él, es como si una dejara de ser mujer cuando se va y vuelvo una a serlo de nuevo cuando vuelve (Isabel).
Roles que cambian en función de las llegadas y partidas de la pareja

Los hijos asumen tareas de mayor responsabilidad.

Reconocimiento de la figura masculina como autoridad en el hogar.

Búsqueda de nuevas relaciones sociales que mitiguen el sufrimiento.

Sufrimiento continuo por la ausencia

Se busca a la familia de origen como fuente de protección.

Añoranza por vivirse como mujer. Se es madre, pero no esposa. 
46. A nadie se le ocurre pensar que necesito un abrazo, una mano cariñosa... y así se van pasando los años hasta que a uno se le olvida esa necesidad de ser mujer, de tener pues, relaciones (Isabel).

47. Al principio lo extrañaba mucho, usted sabe que la critican a uno si no se da a respetar, como dicen por ahí, pueblo chico infierno grande, uno tiene que olvidarse de ser coqueta, de agradarle a un hombre (Elizabeth).

48. Él siempre fue muy tranquilo en ese aspecto de la intimidad, yo también, hasta que se tuvo que ir, entonces valoré lo que es tener a un hombre siempre, a la disposición, te acostumbras a que esté ahí y cuando no está, si se extrañan los abrazos (Emelia)

49. Una vez un viejito me dijo que nos juntáramos, que su esposa había muerto y ocupaba quien le diera de comer, le lavara y le planchara, primero me dijo: si su marido anda en el norte, ya no lo espere, goce la vida, disfrútela, tuve que decirle a mi hermano para que lo calmara (Josefina).

50. Muchas veces me han propuesto cosas... sólo pasear... me ven sola los hombres...ni lo pienso, sólo imaginarme que por eso ya no me dará para mis hijos, sus estudios, lo pienso bien, me digo...eso no lo hace una mujer decente... llegué a tener problemas, me castigó mandándome poco dinero, según él, por si me lo gastaba con otra persona (Emelia).
Se reprime la sexualidad en las mujeres en función de lo deseable socialmente.

Se extraña el acercamiento físico con la pareja.

Se busca apoyo en hombres de la familia de origen para que funjan como sus protectores ante el cortejo de otros.

En ausencia de la pareja, viven acoso de hombres de la comunidad, lo cual rechazan. 
Afirmaciones significativas

Centro de Investigación sobre Desarrollo Humano y Sociedad
51. Veo que los muchachos si ya están bien, ya salieron adelante...pero vivían tristes, se les veía en su carita, a mí me dolía mucho, mucho... quisiera llenarles ese vacío, pero sé que no será así, un padre es un padre...aunque yo creo que yo sufría todavía más, tenía que cargar con mi pena, más la de ellos (Emelia).

52. Yo he tenido que lidiar sola...mis niños también sufrieron lo mismo cuando mi marido se fue (Norma).

53. Lo más, más duro, es siempre el primer año, como cuando se muere alguien también, es algo parecido...pasar las fiestas de Navidad, o el día del padre, los cumpleaños, se les extraña muchísimo (Guadalupe)

54. En un principio sentía como que él me quería, como que me extrañaba, fueron pasando los días y ahora ya no siento eso, siento que solo nos ve como una obligación, como diciendo, ya cumplí mandándoles, ya vean por ustedes (Laura).

55. Dura, la situación fue dura, primero me refugié en mis hijos, pero...fíjese...vi que los afectaba, pues me pongo llore y llore, y lloro todavía (Elizabeth).

56. Si ocupo que alguien me ayude o que yo ayude a alguien, siempre es mi mamá o hermanas, cuñadas o concuñas (Rosa).

57. Me hice de buenas relaciones con mis hermanas y cuñadas, porque ellas son las que me han cuidado (Norma).
Sentimientos de soledad y sufrimiento en el núcleo familiar.

El primer año se viven en mayor medida las dificultades afectivas de la ausencia.

Se percibe que el afecto se diluye con el tiempo.

Los hijos como refugio en el dolor crónico.

Las mujeres de la familia representan una fuente de apoyo.

La familia de origen toma el papel de cuidar a la participante. 


\begin{tabular}{l} 
Afirmaciones significativas \\
\hline 58. Lo extrañé mucho, mucho, dicen \\
por ahí que la pareja es a veces hasta más \\
importante que los hijos, pues él, es el \\
compañero...los hijos tarde o temprano \\
se van, quien se queda son ellos, los \\
maridos (Rosa).
\end{tabular}

59. Ahora para ya no estar triste, mejor voy y me confieso con el padrecito...me hecho el atole con la comadre, lloro, pero ya no dejé que mis hijos me vieran tanto (Elizabeth).

60. Se pierde para siempre al esposo, estuvo 22 años fuera, ya nunca fue lo mismos, vino a la boda de mi hija y lo desconocía, bueno al menos como esposo, ya no nos llevamos bien, lo respeto, pero él a mí no (Isabel)

61. Ya no me obedecían los muchachos, cuando estaba él, andaban derechitos, derechitos, con un grito entendían y sino su trancazo cuando era necesario, tenía que venir su tío, hermano de mi esposo a regañarlos, y tratarlos mal, no me gustaba, a veces el regaño era duro, hasta golpes hubo... sino se me descarrilaban" (Rosa).

62. Como ya no podía con mis hijos...que se portaran bien, me obedecieran, pu's eran pura calle, en una ocasión le hablé a mi cuñado, vino y le pego, platicó con él, parece que entendió un poco (Norma).

63. Uno de mis hermanos se lo tomó en serio y se puso como el papá, se lo llevaba a trabajar para que no anduviera en malos pasos (Josefina).
Se realizan acciones con personas externas al núcleo familiar que mitigan la pena.

Sentimientos crónicos de soledad, carencia afectiva, de pérdida de la pareja,

Con la ausencia del padre, se dificulta a la madre el control de la conducta de los hijos, interviene la familia política.

Búsqueda de apoyo en la familia política para controlar la conducta de los hijos.

Búsqueda de apoyo en la familia de origen para controlar la conducta de los hijos. 
Afirmaciones significativas

Centro de Investigación sobre Desarrollo Humano y Sociedad
64. Mi coco ha sido cuando mis hijos no quieren agarrar su camino, cuando se iban de borrachos, de vagos y no querían trabajar, esos eran mis dolores de cabeza (Rosa).

65. Cuando se fue él, mi hijo mayor estaba más pequeño, nos unimos más, sin embargo ahora ya pasaron ocho años y es un jovencito, pero no quiere componerse, no quiere estudiar, ni trabajar, ni ayudarme en la casa... solo cuando le habla su papá se compone unos días y luego vuelve a lo mismo, pienso yo que necesita una mano fuerte... hasta a alguien que lo escuche... y no lo tiene (Nancy).

66. Mi esposo decidió llevarse mejor a sus hijos a trabajar con él, aquí nomás no se componían (Isabel).

67. Yo siempre estuve preocupada por darles de comer, lavar, planchar, los animales, que iba yo a estar pensando en llevarlos a un lado...como hoy, que ya los llevan que a fútbol o computación, antes ni había eso, daban clases de cocina y de otras cosas, me llamaba la atención, pero que iba yo a poder ir, mis hijos menos, ellos juagaban en la casa (Josefina).

68. Salir lo que se dice salir, nunca lo hicimos, cuando estaba él, íbamos a dar una vuelta al zócalo cuando había fiesta del santo patrono, éramos mayordomos y teníamos que estar pendientes, desde que se fue para el otro lado, ya no participo, ocupan a la pareja completa, pero tampoco iba a la fiesta no podía sola con tanto chamacal... ahora salgo un poquito más (Hortensia).
Efecto pasajero del control del padre en la distancia.

Los hijos migran por indicaciones del padre.

Las actividades del hogar limitan el interés en que los hijos realicen actividades recreativas.

La vida social limitada antes y después de la partida del padre. 


\begin{abstract}
69. Cuando voy pa'l mercado me encuentro a las vecinas, la comadre de bautizo de mi hija y la de mis otros hijos menores, nos compramos una paleta, nos sentamos en el jardín y que rico ratito paso, esa es mi distracción, a uno le hace falta de vez en cuando (Norma).
\end{abstract}

70. Nunca fui de amigas, tengo a mis comadres, y todas las mañanas platico con mi vecina un ratito mientras barremos la entrada de la casa (Guadalupe).

71. Nuestra diversión era cuando es la fiesta de la virgencita, vamos a los juegos, nos comemos uno antojitos mexicanos, que el pambazo, el pozole, a veces jugamos lotería. Lo mismo cuando él viene, le encanta venir en esas fechas. (Elizabeth).

72. Mi esposo antes de que se fuera, era, bueno éramos pues, bueno todavía es como si fuera, porque manda dinero para la iglesia. Éramos mayordomos de la iglesia, entonces cuando viene, llega a ver que se le ofrece al padre y cooperar, también le gusta venir en Navidad y día de muertos (Guadalupe).
En las actividades cotidianas se generan lugares de encuentro

Se disfrutan los pequeños momentos de recreación con vecinos.

Festejar las fiestas religiosas y tradiciones se vuelven las actividades recreativas más constantes.

Participación en tradiciones, mantienen vinculado al migrante en su lugar de origen. 
Conglomerados temáticos con sus Significados formulados asociados.

\section{Significados formulados asociados}

1. La estructura familiar no cambió con la partida del padre.

2. Al padre está ausente pero se le percibe como integrante de la familia.

3. En la distancia se mantiene la alianza del matrimonio.

4. Dificultades económicas para lograr que el esposo migre. El apoyo de la familia de origen está presente.

5. Pérdida de patrimonio para lograr que el padre migre.

6. Endeudamiento para lograr que el esposo migre.

7. Carencia económica inicial que se compensa con bienestar económico posterior.

8. Mejoró la alimentación de la familia con las primeras remesas recibidas.

9. Acceso a alimentos fuera de la canasta básica.

10. Mejoró la situación financiera de la familia, pero no hay exceso económico.

11. La familia política adquiere la tutela en de la familia de las participantes, con la autorización del migrante.

12. Inconformidad porque cuñados y suegros se hacen cargo de las finanzas de la familia del migrante.

13. Disgusta la intromisión de la familia política en la autoridad del hogar.

Resolución de problemas afectivos

\section{Conglomerado temático}

La estructura familiar se mantiene
Resolución eficaz de problemas instrumentales

14. Lucha constante para imponerse como jefa de familia.

15. Se desestabilizaron los hijos y la madre toma el mando.

16. Se autopercibe como mujer sola.

17. Percepción de que socialmente fue vista como mujer sola, que la pareja otorga valor como mujer y esposa.

18. La comunicación se llevó a cabo por teléfono y correo postal.

19. Inicialmente la comunicación se centró en los hijos, primero sobre su infancia y después en sus actividades como jóvenes y adultos.

20. Habituación a la comunicación escasa. 
21. Comunicación que gradualmente fue más concreta (centrada en la economía del hogar) y menos emocional.

22. Comunicación constante y emocional al inicio, cambiante en el tiempo

23. Comunicación que gradualmente fue menos afectiva.

Conglomerado temático

24. Añoranzas por los alimentos típicos del lugar de

Comunicación afectiva

confusa e indirecta origen.

25. Planeación sobre alimentos que se consumirán al regreso al país natal.

26. Planes recreativos para el futuro.

27. Planes en torno a la casa familiar.

28. La familia política como motivo de comunicación conflictiva.

29. Los hijos inicialmente no vieron a la madre como figura de autoridad.

30. Esfuerzo de la madre para imponerse como figura de autoridad.

31. Búsqueda de estrategias de la madre para recuperar autoridad con los hijos.

32. El esposo en la distancia busca la forma de estar enterado de las acciones de la esposa.

Roles centrados en el control de conducta

33. El migrante mantiene el control con la esposa en la distancia.

34. Con el control del migrante en la distancia, la esposa prefiere su ausencia.

35. Familia política que vigila la conducta de las participantes.

36. Intromisión de familia política que torna compleja la educación de los hijos.

37. Roles que se tornan difusos en cuanto a límites Roles centrados en los límites y autoridad con los hijos.

38. Se redistribuyen las tareas en el hogar.

39. Roles que cambian en función de las llegadas y partidas de la pareja

40. Los hijos asumen tareas de mayor Los roles se revisan responsabilidad.

41. Reconocimiento de la figura masculina como autoridad en el hogar. 
42. Búsqueda de nuevas relaciones sociales que mitiguen el sufrimiento.

43. Sufrimiento continuo por la ausencia

Búsqueda de roles de afectividad

44. Se busca a la familia de origen como fuente

Conglomerado temático de protección.

45. Añoranza por vivirse como mujer. Se es madre, pero no esposa.

46. Se vive la sexualidad en función de las llegadas y partidas de la pareja.

47. Represión de la sexualidad en las mujeres en

Roles afectivos de gratificación función de lo deseable socialmente.

y ароуо

48. Se extraña el acercamiento físico con la pareja.

49. Búsqueda de apoyo en hombres de la familia

de origen para que funjan como sus protectores ante el cortejo de otros.

50. Vacío y soledad de las madres y los hijos que permanece en el tiempo.

51. Sentimientos de soledad y sufrimiento en el núcleo familiar.

52. El primer año se viven en mayor medida las Involucramiento afectivo escaso dificultades afectivas de la ausencia.

53. El afecto se diluye con el tiempo.

54. Los hijos son refugio en el dolor crónico.

55. Las mujeres de la familia representan una fuente de apoyo.

56. La familia de origen toma el papel de cuidar a la participante.

57. El migrante es un compañero insustituible.

58. Se realizan acciones con personas externas al núcleo familiar que mitigan la pena.

Respuestas afectivas

59. Sentimiento crónico de soledad y de pérdida de la pareja.

60. Se dificulta a la madre el control de la conducta de los hijos pues interviene la familia política.

61. Búsqueda de apoyo en la familia de origen para controlar la conducta de los hijos.

62. Se busca el apoyo en la familia política para controlar la conducta de los hijos. sexual adulta ausentes

63. Conductas nocivas en los hijos que las madres no pueden controlar.

64. Control pasajero del padre en la distancia.

65. Los hijos también migran por indicaciones del padre.

Control de conducta caótico en situaciones que involucran peligro físico 


\section{Significados formulados asociados Conglomerado temático}

66. Las actividades del hogar limitan el interés en que los hijos realicen actividades recreativas.

67. Vida social limitada antes y después de la migración.

68. Las actividades cotidianas generan lugares de encuentro

69. Se disfrutan los pequeños momentos de recreación con vecinos.

70. Las actividades recreativas son las fiestas religiosas y tradiciones.

71. Las tradiciones mantienen vinculado al migrante en su lugar de origen.

72. Participación en tradiciones, mantienen vinculado al migrante en su lugar de origen.
Control de conducta rígido en situaciones que requieren sociabilización 


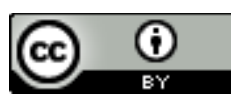

Este texto está protegido por una licencia $\underline{\text { Creative Commons }}$ 4.0.

Usted es libre para Compartir — copiar y redistribuir el material en cualquier medio o formato- y Adaptar el documento - remezclar, transformar y crear a partir del material — para cualquier propósito, incluso comercialmente, siempre que cumpla la condición de:

Atribución: Usted debe reconocer el crédito de una obra de manera adecuada, proporcionar un enlace a la licencia, e indicar si se han realizado cambios. Puede hacerlo en cualquier forma razonable, pero no de forma tal que sugiera que tiene el apoyo del licenciante o lo recibe por el uso que hace.

Resumendelicencia - Textocompletodelalicencia 